Revista de Derecho Público: Teoría y Método

\title{
APROXIMACIÓN A LA INTERPRETACIÓN CONFORME COMO TÉCNICA DE COORDINACIÓN NORMATIVA*
}

\section{CONSISTENT INTERPRETATION AS AN INSTRUMENT TO ENSURE COHERENCE BETWEEN LEGAL ORDERS}

\author{
Xabier Arzoz Santisteban \\ Catedrático de Derecho Administrativo \\ UNED \\ xarzoz@der.uned.es \\ http://orcid.org/0000-0002-3976-4265
}

RESUMEN: Este trabajo pretende contribuir al estudio de la interpretación conforme como técnica de coordinación entre ordenamientos jurídicos. Aunque la modalidad primigenia y más destacada en el derecho comparado es el principio de interpretación conforme a la Constitución, existen otras modalidades más complejas, como la interpretación conforme a los tratados internacionales sobre derechos humanos y al derecho de la Unión Europea. El artículo, en la primera parte, ofrece una vista panorámica de la consolidación del principio de interpretación conforme al derecho internacional de los derechos humanos en el continente europeo, para dar cuenta de su creciente protagonismo como técnica de coordinación normativa en el derecho comparado. En la segunda parte formula una teoría general de la interpretación conforme, elaborada a partir de los rasgos comunes de los tres subprincipios de interpretación conforme reconocidos en el ordenamiento jurídico español. En la tercera parte se regresa al punto de partida, que es el principio de interpretación conforme a la Constitución. Aunque este principio rige de forma aparentemente indiscutida para todos los operadores jurídicos, se detecta una cierta anemia en su aplicación por la jurisdicción

* Trabajo finalizado el 28 de septiembre de 2021. Abreviaturas utilizadas: Ar. - Repertorio Aranzadi de Jurisprudencia; ATC - Auto del Tribunal Constitucional; CC - Código Civil; CE - Constitución Española; CEDH - Convenio Europeo de Derechos Humanos; FJ - Fundamento Jurídico; LOPJ - Ley Orgánica del Poder Judicial; LOTC - Ley Orgánica del Tribunal Constitucional; STC - Sentencia del Tribunal Constitucional; SSTC - Sentencias del Tribunal Constitucional (España); STS - Sentencia del Tribunal Supremo; SSTS - Sentencias del Tribunal Supremo; TEDH - Tribunal Europeo de Derechos Humanos; TFUE - Tratado de Funcionamiento de la Unión Europea. 
contencioso-administrativa española. Por ello, se indagará en las causas de la asimetría entre el valor dogmático atribuido al principio en el plano discursivo y su uso limitado en la práctica de los jueces ordinarios, que no del juez constitucional.

PALABRAS CLAVE: Interpretación constitucional, derechos humanos, derecho internacional, derecho de la Unión Europea, control de la ley, derecho constitucional comparado, órganos judiciales, jurisdicción contencioso-administrativa, división de poderes.

ABSTRACT: This paper aims at studying the doctrine of consistent interpretation as an instrument to ensure coherence between legal orders. The first modality to appear and the most extend one in comparative terms is the duty of judges to interpret law in accordance with the national Constitution. New modalities have, nevertheless, emerged, at least in Spain and other European states, such as the duties of national courts to interpret national law in accordance with international human rights treaties and with EU law. By interpreting national law in conformity with international or EU obligations, national courts can ensure, first, that those obligations are made effective in the national legal order and, second, that domestic law is construed so as not to conflict with international and EU law, avoiding the legal consequences of a breach. This paper provides, first, a panoramic view of the expanding of the principle of consistent interpretation regarding international human rights treaties, to show the increasing international relevance of that doctrine. It then reviews the foundations and limits of the practice of consistent interpretation, drawing criteria from the application of the three modalities already mentioned. Finally, it goes back to the original modality of the doctrine, interpretation of law in accordance with the Constitution, to inquiry its poor use in administrative review in Spain, despite its undisputed value.

KEYWORDS: Constitutional interpretation, human rights, international law, EU law, judicial review, comparative constitutional law, national courts, administrative review, separation of powers.

SUMARIO: 1. INTRODUCCIÓN.-2. LA INTERPRETACIÓN CONFORME A LOS DERECHOS HUMANOS RECONOCIDOS EN EL ÁMBITO INTERNACIONAL COMO TÉCNICA DE COORDINACIÓN ENTRE ORDENAMIENTOS.-3. TEORÍA GENERAL DE LA INTERPRETACIÓN CONFORME: 3.1. Concepto, naturaleza y fundamento; 3.2. Función; 3.3. Modalidades; 3.4. Límites.-4. LA INTERPRETACIÓN CONFORME EN EL MARCO DE LOS CONTROLES SOBRE LA LEY: 4.1. De la teoría a la realidad: la asimétrica práctica de la interpretación conforme a la Constitución; 4.2. La conexión entre el poder de inaplicación de la Ley y la práctica de la interpretación conforme.-5. CONCLUSIÓN.-6. BIBLIOGRAFÍA

\section{INTRODUCCIÓN}

Este trabajo pretende contribuir al estudio de un fenómeno en expansión: la configuración normativa o jurisprudencial de modalidades de interpretación conforme como forma de coordinar ordenamientos jurídicos plena o parcialmente autónomos entre sí. La modalidad primigenia y más destacada en el derecho comparado es, sin duda, el principio de interpretación conforme a la Constitución del entero ordenamiento estatal. Junto a ella, emergen nuevas modalidades más complejas y ambicio- 
sas. Por lo que respecta al ordenamiento jurídico español, que es la perspectiva desde la que se reflexionará en el presente estudio, existen al menos otras dos modalidades o subprincipios de interpretación conforme: a los tratados internacionales sobre derechos humanos y al derecho de la Unión Europea. Todas esas modalidades tienen en común la posibilidad que ofrecen de reducir las fricciones y compatibilizar el contenido de normas pertenecientes a distintos ordenamientos o subsistemas jurídicos, atendiendo a una norma prioritaria.

En el limitado espacio disponible no es posible realizar un análisis detallado del principio general de interpretación conforme o de los tres subprincipios señalados. Por ello, la atención debe centrarse en un número reducido de cuestiones.

Se comenzará con una panorámica de la consolidación del principio de interpretación conforme al derecho internacional de los derechos humanos en el continente europeo, que dé cuenta de su creciente protagonismo en el derecho comparado como técnica ordinaria de coordinación entre el ordenamiento estatal y el internacional.

Las modalidades de interpretación conforme presentan al mismo tiempo rasgos comunes y específicos. Algunos autores han explorado en alguna medida las concomitancias con otras obligaciones de interpretación conforme, más con el objetivo de mejor entender la concreta modalidad analizada que para ofrecer una visión general de la técnica ${ }^{1}$. Por ello, en un segundo apartado, partiendo de los rasgos comunes de los tres subprincipios de interpretación conforme reconocidos en el ordenamiento jurídico español, se intentará elaborar por vía inductiva lo que podría denominarse una "teoría general de la interpretación conforme". A tal fin se analizarán el concepto y el fundamento, la función, las modalidades y los límites de la interpretación conforme.

En tercer lugar, el estudio vuelve al punto de partida, que es sin duda el principio de interpretación conforme a la Constitución. Aunque este principio rige de forma aparentemente indiscutida para todos los operadores jurídicos, se detecta una cierta anemia en su aplicación por la jurisdicción contencioso-administrativa española. Por ello, se indagará en las posibles causas de la asimetría entre el valor dogmático atribuido al principio de interpretación conforme a la Constitución en el plano discursivo y su uso limitado en la práctica de los jueces ordinarios, que no del juez constitucional. En particular se reflexionará sobre la relación entre el reconocimiento de un poder de inaplicación de la ley y la práctica efectiva de la interpretación conforme y se formularán algunas hipótesis. Finalmente, una conclusión cerrará el trabajo.

1 Compárese Gerrit BETLEM, "The doctrine of consistent interpretation - Managing legal uncertainty”, Oxford Journal of Legal Studies, vol. 22, núm. 3, 2002, pp. 397-418, que relaciona la obligación de interpretación conforme a las directivas europeas y la obligación de interpretación conforme prevista en la UK Human Rights Act 1998. Por su parte, Hèctor LÓPEZ BOFILL, Decisiones interpretativas en el control de constitucionalidad de la ley, IVAP-Tirant lo Blanch, Valencia, 2004, aunque atiende sobre todo al principio de interpretación conforme a la Constitución en sede constitucional, su investigación analiza también la práctica británica derivada de la UK Human Rights Act así como, brevemente, las obligaciones de interpretación conforme derivadas del art. 10.2 CE y de la jurisprudencia del Tribunal de Justicia. 


\section{LA INTERPRETACIÓN CONFORME A LOS DERECHOS HUMANOS RECONOCIDOS EN EL ÁMBITO INTERNACIONAL COMO TÉCNICA DE COORDINACIÓN ENTRE ORDENAMIENTOS}

El derecho constitucional comparado conoce tres formas básicas de procurar la armonización entre el derecho constitucional material y el derecho internacional de los derechos humanos: la inclusión de reservas en los tratados internacionales sobre derechos humanos, la previsión expresa de la utilización de los tratados internacionales como criterios de interpretación de los derechos constitucionales y la constitucionalización directa de los derechos humanos reconocidos en el ámbito internacional ${ }^{2}$. El objetivo de este apartado es examinar la extensión de la interpretación conforme a los tratados internacionales sobre derechos humanos como técnica de coordinación normativa utilizada de forma prevalente en el ámbito europeo.

Mientras la inclusión de reservas en los tratados internacionales representa una forma de coordinación puramente defensiva del ordenamiento constitucional, las otras modalidades mencionadas constituyen formas de coordinación más o menos "amistosas" o "abiertas" en relación con el ámbito supraestatal. Desde la perspectiva de la indicada clasificación, la Constitución española consagra, mediante el art. 10.2 $\mathrm{CE}$, una vía intermedia de coordinación moderadamente abierta. Ahora bien, ello dista de ser la pauta o el término medio en el derecho comparado europeo: las constituciones de la mayoría de los Estados europeos no han optado explícitamente por instrumentos "amistosos" de coordinación con el derecho internacional de los derechos humanos (la segunda y la tercera de las tres modalidades antes señaladas), aunque, como veremos, la segunda modalidad está conociendo un protagonismo cada vez mayor.

Solo tres Estados europeos, Austria, Países Bajos y la República Checa han adoptado una forma de la más intensa modalidad de coordinación. En 1964 se reconoció en Austria rango constitucional al Convenio Europeo de Derechos Humanos y a todos sus Protocolos (salvo al núm. 12); y, en consecuencia, los derechos reconocidos en esos instrumentos normativos pueden ser invocados tanto ante los tribunales ordinarios como ante el Tribunal Constitucional. ${ }^{3}$ En los Países Bajos, el Convenio tiene

2 Al respecto puede verse, con ejemplos, Karl-Peter SOMMERMANN, "Völkerrechtlich garantierte Menschenrechte als Maßstab der Verfassungskonkretisierung - Die Menschenrechtsfreundlichkeit des Grundgesetzes", Archiv des öffentlichen Rechts, vol. 114, 1989, pp. 391-422, especialmente 395 ss. Lo cual no impide que, al mismo tiempo, el derecho constitucional también pueda prever técnicas para garantizar la supremacia de la Constitución y los mecanismos de producción normativa que esta consagra en relación con los tratados internacionales, como el control preventivo o represivo de constitucionalidad de los tratados; véase en este sentido, para el ordenamiento constitucional español, el art. 95.2 CE y los arts. 27.2.c) y 78 LOTC.

3 Christoph GRABENWARTER, Europäische Menschenrechtskonvention, 4. ${ }^{\mathrm{a}}$ ed., C.H. Beck/Helbing Lichtenhahn/Manz, Múnich/Basilea/Viena, 2009, p. 16. 
rango superior al conjunto del ordenamiento jurídico, incluida la Constitución ${ }^{4}$. En la República Checa el Convenio tiene rango constitucional de forma indirecta: constituye parámetro legal de control en el examen de los recursos de amparo, junto a los derechos fundamentales reconocidos en el ámbito interno ${ }^{5}$.

La segunda modalidad de coordinación antes mencionada es, originalmente, una fórmula desarrollada por las Constituciones portuguesa y española de 1976 y 1978, respectivamente. Estas dos Constituciones, bajo la impresión viva de la experiencia histórica de sendos regímenes dictatoriales, fueron pioneras en consagrar mediante disposiciones constitucionales la vinculación del intérprete de los derechos fundamentales con garantías internacionales de los derechos humanos. Lo que pudo quedarse en una declaración de intenciones y en un compromiso político con el acervo internacional en materia de derechos humanos se ha convertido en una técnica jurídica innovadora de adaptación y coordinación del ordenamiento jurídico con las obligaciones contraídas por el Estado en el plano internacional ${ }^{6}$.

El art. 10.2 CE realiza dos funciones: la actualización permanente del contenido de los derechos fundamentales constitucionales y la coordinación de la interpretación más o menos introvertida de los derechos fundamentales con el estándar internacional de protección de los derechos humanos, de forma que ambos marcos de protección evolucionen concertadamente; coordinación que no se quiere garantizar únicamente en el plano de la legalidad (lo que ya garantiza, para el caso español, el art. $96 \mathrm{CE}$ ) sino en el plano más elevado del ordenamiento interno, el de la constitucionalidad. Con su inclusión en las declaraciones y acuerdos internacionales y su posterior ratificación por los Estados, una parte de los derechos fundamentales ha dejado de ser solo límites internos (estatales) a los poderes públicos para convertirse también en límites externos (supraestatales). Ello da paso al Estado internacionalmente limitado por el derecho internacional de los derechos humanos ${ }^{7}$. Sin duda ello no es más que una

4 El art. 93 de la Constitución de los Países Bajos dispone que "las normas de los tratados y las resoluciones de las organizaciones de derecho internacional público con efectos vinculantes generales por su contenido, tendrán fuerza obligatoria a partir de su publicación". El art. 94 señala que "las disposiciones legales en vigor en el Reino no serán aplicadas si su aplicación no fuese compatible con las normas de los tratados, o las resoluciones de derecho internacional público, con efectos vinculantes generales".

5 Vid. Martje DE VISSER, Constitutional Review in Europe. A Constitutional Analysis, Hart, Oxford, 2015, pp. 235-236.

6 Diego J. LIÑÁN NOGUERAS, "El proyecto constitucional europeo y la interpretación de derechos y libertades en la Constitución española: ¿una nueva dimensión del art. 10.2 CE?”, en Pacis artes. Obra homenaje al Profesor Julio D. González Campo, vol. 1, Universidad Autónoma de Madrid, Madrid, 2005 , p. 933, señala que constituye "el más innovador y el que mayor sustancia normativa" contiene de los tres preceptos constitucionales que regulan el modelo de vinculación del sistema constitucional español con el sistema jurídico internacional (arts. 10.2, 93 y 96 CE) y "uno de los instrumentos de política jurídica más útiles y exitosos de la CE”.

7 Vid. el concepto y la puesta en relación con el art. 10.2 en Alejandro SÁIZ ARNÁIZ, La apertura constitucional al derecho internacional y europeo de los derechos humanos. El artículo 10.2 de la Constitución española, CGPJ, Madrid, 1999, p. 52 y ss. Para este autor, el art. 10.2 expresaría "la radical alteración que se ha producido en el terreno de los derechos de la persona en relación con el derecho internacional y el derecho nacional, al pasar éste de influir a ser influido; de condicionar, en aras de la defensa de la 
de las facetas de la incipiente apertura internacional del Estado constitucional clásico (introvertido). El proceso interno de positivización de los derechos fundamentales como límites y vínculos sustanciales para el legislador se coordina, a través de cláusulas con el contenido y el alcance del art. 10.2, con el proceso externo de positivización de los derechos fundamentales como límites y vínculos sustanciales para los Estados. Mediante la cláusula de interpretación conforme el Estado constitucional de derecho exterioriza su voluntad de coordinación con el Estado internacionalmente limitado por el derecho internacional de los derechos humanos. Desde el inicio de su jurisprudencia, el Tribunal Constitucional español ha subrayado la importante función coordinadora que despliega el art. 10.2 $\mathrm{CE}^{8}$.

En la década de los años noventa del siglo pasado, la segunda modalidad de coordinación antes mencionada se extendió a nuevas Constituciones, con la oleada de constitucionalismo en el Centro y el Este de Europa a partir de 1989. Aunque esos Estados europeos se han caracterizado, en el marco de procesos intensos de reforma constitucional, por ratificar e incorporar inmediatamente el Convenio al ordenamiento interno y por reconocer constitucionalmente la primacía de los tratados internacionales de derechos humanos sobre la legislación interna ${ }^{9}$, solo dos Estados parecen haber adoptado una cláusula expresa de coordinación con el derecho internacional de los derechos humanos. En cualquier caso, el modelo de inspiración para esa adopción es inequívoco. El art. 10.2 CE ha sido reproducido casi textualmente en las Constituciones de Rumania y de la República Moldava (un curioso caso de afinidad latina de un extremo a otro del continente europeo) ${ }^{10}$. También recuerda intensamente al art. 10.2 CE el art. 52.3 de la Carta de Derechos Fundamentales de la Unión Europea ${ }^{11}$. Indirectamente el precepto obliga a coordinarse con la jurisprudencia del Tribunal Europeo de Derechos Humanos, pues de otra forma no se podrá

soberanía estatal en un sector particularmente sensible para la misma como son las relaciones entre los ciudadanos y sus autoridades públicas, a ser condicionado" (p. 54).

8 Para el Tribunal Constitucional español, España asume en virtud del art. 10.2 "un sistema de valores y principios de alcance universal" (STC 21/1982, FJ 10); "la Constitución se inserta en un contexto internacional en materia de derechos fundamentales y libertades públicas, por lo hay que interpretar sus normas en esta materia de conformidad con la Declaración Universal de Derechos Humanos y los tratados y acuerdos internacionales que menciona el precepto (art. 10.2 CE)" (STC 78/1982, FJ 4).

9 Jörg POLAKIEWICZ, "The Status of the Convention in National Law", en Robert BLACKBURN y Jörg POLAKIEWICZ (eds.), Fundamental Rights in Europe. The ECHR and its Member States, 1950-2000, Oxford, Oxford University Press, 2001, pp. 40-41.

10 Disposiciones similares al art. 10.2 CE se encuentra también en varias Constituciones latinoamericanas: Perú (disposición final y transitoria cuarta), Bolivia (art. 13.III), Colombia (art. 93.2), Ecuador (art. 424), etc. Otras constituciones, como la Constitución de la República Bolivariana de Venezuela (art. 23), incluyen una técnica de coordinación más intensa, al reconocer la prevalencia de los tratados internacionales sobre derechos humanos en la medida que contengan normas más favorables a las establecidas en la Constitución y en las leyes.

11 "En la medida en que la presente Cara contenga derechos que correspondan a derechos garantizados por el Convenio Europeo para la Protección de los Derechos Humanos y de las Libertades Fundamentales, su sentido y alcance serán iguales a los que les confiere dicho Convenio. Esta disposición no obstará a que el derecho de la Unión conceda una protección más extensa." 
garantizar que el "sentido y alcance" de los derechos de la Carta sean "iguales a los que les confiere dicho Convenio" 12 .

Una variante del segundo modelo de coordinación con el derecho internacional de los derechos humanos ofrece la disposición prevista en la Human Rights Act del Reino Unido de 1998, según la cual debe procurarse una interpretación conforme al CEDH. Literalmente dice así la Sección 3, apartado 1: "So far as it is possible to do so, primary legislation and subordinate legislation must be read and given effect in a way which is compatible with the Convention rights". De este precepto destaca el reconocimiento explícito de que no siempre será "posible" alcanzar una interpretación de las leyes británicas conforme al Convenio ${ }^{13}$. La preocupación por la garantía de la coordinación interpretativa en materia de derechos fundamentales es una de las características del moderno Estado constitucional que no se limita a Europa ${ }^{14}$.

Por otra parte, con independencia de la difusión de la cláusula del art. 10.2 CE en algunas Constituciones modernas, se constata la creciente constitucionalización en el derecho comparado de la idea de primacía del nivel de protección internacional siempre que sea superior al nivel interno. En este sentido, el art. 11 de la Constitución de Eslovaquia dispone que "international instruments on human rights and freedoms ratified by the Slovak Republic and promulgated under statutory requirements shall take precedence over national laws provided that the international treaties and agreements guarantee greater constitutional rights and freedoms" ${ }^{15}$. Una cláusula, de efectos similares, de vinculación al nivel de protección internacional superior rige en Bosnia-Herzegovina ${ }^{16}$. Normas constitucionales con este contenido han servido en otros Estados europeos para crear jurisprudencialmente la posibilidad de que los jueces internos controlen la compatibilidad de las leyes nacionales con los tratados internacionales, esto es, para consagrar un contrôle de conventionnalité de la legislación interna. Generalmente se trata de ordenamientos constitucionales en los que no existe un catálogo constitucional de derechos fundamentales, por lo que la coordinación con el derecho internacional de los derechos humanos no tiene lugar en el plano constitucional (mediante la interpretación conforme de los derechos fundamentales

12 Sobre la influencia del CEDH sobre el nivel de protección de la Carta vid. Gero ZIEGENHORN, Der Einfluss der EMRK im Recht der EU-Grundrechtecharta, Duncker \& Humblot, Berlín, 2009.

13 Sobre los problemas de dicha interpretación conforme vid. BETLEM, 2002.

14 Vid. la Constitución de Sudáfrica: "Cuando interpreta la Declaración de derechos, una corte, tribunal o foro: (a) debe fomentar los valores que subyacen a una sociedad abierta y democrática basada en la dignidad humana, la igualdad y libertad; (b) debe considerar el derecho internacional; y (c) puede considerar el derecho extranjero" (sección 39, apartado 1).

15 Vid. la versión inglesa en POLAKIEWICZ, 2001, p. 41.

16 De acuerdo con el art. 2 de la Constitución para Bosnia-Herzegovina derivada del Acuerdo Marco General o Acuerdo de Paz de Dayton, las diversas entidades que conforman Bosnia-Herzegovina garantizarán a todas las personas bajo su jurisdicción "the highest level of internationally recognized human rights and fundamental freedoms", de acuerdo con una lista de tratados internacionales enumerados en el anexo 6. La lista incluye, además del Convenio Europeo y sus Protocolos, los dos Pactos Internacionales y otros doce instrumentos internacionales o europeos. 
incluidos en el catálogo constitucional), sino en el plano legislativo (mediante por la adecuación de las leyes internas a los tratados internacionales ratificados por el Estado).

Así, en Francia, el Consejo de Estado se pronunció en el arrêt Nicolo (1989) en el sentido de que el art. 55 de la Constitución incluía necesariamente la habilitación implícita de los jueces ordinarios para examinar la conformidad de la legislación interna con respecto a los tratados internacionales. Esta sentencia ha sido comparada con Marbury contra Madison, lo que da idea de su importancia en el contexto del ordenamiento jurídico francés ${ }^{17}$.

En los Países Bajos, la posibilidad de controlar la compatibilidad de la legislación interna con los tratados internacionales y de, en su caso, inaplicarla está explícitamente prevista en el art. 94 de la Constitución de 1983 (aunque se introdujo a mediados del siglo xx ${ }^{18}$. Esta expresa habilitación constitucional es muy significativa, si se tiene en cuenta que la Constitución prohíbe expresamente a los jueces la declaración de inconstitucionalidad de la ley: solo se exceptúa la supremacía del Parlamento en beneficio del derecho internacional. Tanto en el caso francés como en el holandés, esto supone que, en la práctica, el CEDH (y otros tratados internacionales relevantes sobre derechos humanos) viene a funcionar como el Bill of rights interno, con independencia de que exista o no un listado constitucional de derechos, porque la única forma disponible para proteger los derechos humanos frente a una ley en vigor pasa por suscitar el control judicial de esa ley de conformidad con aquel Convenio (o con otros tratados internacionales sobre derechos humanos) ${ }^{19}$.

La coordinación en la interpretación de los derechos fundamentales no solo tiene lugar, ni tiene lugar principalmente, cuando esa coordinación ha sido dispuesta expresamente por una norma jurídica, constitucional o no. La falta de una referencia expresa no impide a las jurisdicciones internas tomar en cuenta, por su propia iniciativa, los elementos extraídos de los tratados internacionales y de la doctrina de los órganos de supervisión de esos tratados. De hecho, aun careciendo de un fundamento constitucional explícito como el art. 10.2 CE, las jurisdicciones de los Estados europeos —en especial, las de naturaleza constitucional — suelen procurar en la práctica, y con efectos parecidos, la coordinación de la interpretación de los derechos fundamentales y de las normas del ordenamiento interno de conformidad con las garantías internacionales.

17 Para los pormenores de esa consolidación y los problemas que plantea la dualidad de controles (constitutionnalité y conventionnalité) en materia de derechos fundamentales, véase Joël ANDRIANTSIMBAZOVINA, "L'enrichissement mutuel de la protection des droits fondamentaux au niveau européen et au niveau national. Vers un contrôle de "fondamentalité»", Revue française de droit administratif, 2002, pp. 124-138; y Cécile CASTAING, "L'extension du contrôle de conventionalité aux principes généraux du droit communautaire", Revue trimestrielle de droit européen, núm. 39, 2003, pp. 197-228.

18 Vid. supra, nota 4.

19 Monica CLAES, The national courts' mandate in the European constitution, Hart, Oxford, 2006, p. 705. 
La utilización del derecho internacional de los derechos humanos para interpretar los derechos constitucionales o para orientar la legislación interna tiene lugar en grados diferentes y viene condicionada por circunstancias diversas (como la existencia de un catálogo constitucional de derechos o la existencia de una jurisdicción constitucional especializada para su tutela), pero es una tendencia que se puede constatar en el ámbito europeo, sobre todo en relación con el Convenio Europeo, sus Protocolos y la doctrina del TEDH ${ }^{20}$.

Así, el Tribunal Constitucional Federal alemán ha señalado que la jurisprudencia del TEDH sirve como "instrumento interpretativo" para definir el contenido y el alcance de los derechos y principios de la Ley Fundamental de Bonn. El Tribunal alemán señala que el Convenio proporciona "una máxima para la interpretación de la Ley Fundamental" y pone de manifiesto que los derechos fundamentales se deben entender como acuñación de los derechos humanos y que aquellos incorporan a estos como estándar mínimo. En la medida en que existen varias interpretaciones posibles, debe darse la preferencia a la interpretación conforme al Convenio y a la jurisprudencia del TEDH. El límite está en la limitación o reducción del nivel de protección resultante de la Ley Fundamental. Los efectos internos de las decisiones del TEDH no se limitan al concreto supuesto de hecho sobre el que versan, pues la Ley Fundamental desea evitar conflictos entre las obligaciones internacionales de Alemania y el derecho nacional ${ }^{21}$.

Otros tribunales constitucionales o supremos europeos han adoptado posturas similares y se sirven igualmente del Convenio y de la jurisprudencia del TEDH para interpretar los derechos fundamentales constitucionales, o avanzan progresivamente en esa dirección ${ }^{22}$. La interpretación constitucional o legal secundum Conventionem no es, en definitiva, más que una consecuencia objetiva de la necesidad de cumplir plenamente con las obligaciones internacionales ${ }^{23}$. Así pues, con o sin art. 10.2 CE,

${ }^{20}$ Referencias para una treintena de Estados en relación con el CEDH pueden verse en Robert BLACKBURN y Jörg POLAKIEWICZ (eds.), Fundamental Rights in Europe. The ECHR and its Member States, 1950-2000, Oxford University Press, Oxford, 2001; el ya citado capítulo, en dicho volumen, de Polakiewicz, 2001, pp. 46-49 sintetiza las más importantes. Un estudio para Suiza, Alemania y Canadá en relación con los Pactos Internacionales de 1966, en Jeanine DE VRIES REILINGH, L'application des Pactes des Nations Unies relatifs aux droits de l'homme de 1966, Basilea, 1998.

21 Vid. sentencias de la Sala Segunda de 14 octubre de 2004, 2 BvR 1481/04, apartados 32, 6263, y de 4 de mayo de 2011, 2 BvR 2365/09, apartados 87-94. Doctrina que no pasó inadvertida al $\mathrm{TEDH}$, el cual en sentencia posterior a la última citada constató con satisfacción el criterio del Tribunal Constitucional Federal de interpretar las disposiciones de la Ley Fundamental con arreglo al Convenio y a la doctrina del TEDH: vid. sentencia del TEDH de 9 de junio de 2011, Schmitz c. Alemania, $\$ 41$.

${ }^{22}$ Es el caso de Italia (sentencias 348/2007 y 349/2007, ambas de 22 de octubre, y 49/2015, de 14 de enero, del Tribunal Constitucional italiano) y de Hungría (sentencia 36/2013, de 5 de diciembre, del Tribunal Constitucional húngaro). Para ANDRIANTSIMBAZOVINA, 2002, p. 136, el Conseil constitutionnel francés hace ya implícitamente una interpretación en este sentido; lo que faltaría es que abandonara la forma "clandestina" en la que lleva a cabo la interpretación de los principios constitucionales a la luz de los derechos fundamentales internacionales y comunitarios.

23 Para Javier GARCÍA ROCA, "El diálogo entre el Tribunal Europeo de Derechos Humanos y los tribunales constitucionales en la construcción de un orden público europeo", Teoría y Realidad Consti- 
la tendencia de los ordenamientos constitucionales camina en dirección a la formación de una Carta jurisprudencial de derechos que no está limitada a los derechos fundamentales derivados de las disposiciones constitucionales, sino que incluye también los derechos garantizados por el derecho internacional y europeo.

La influencia creciente de la jurisprudencia del TEDH en las jurisdicciones de los Estados parte se basa en circunstancias inexistentes en las primeras décadas de actividad de ese órgano judicial: la ratificación del Convenio y el reconocimiento de su jurisdicción para conocer de las demandas presentadas por los particulares por los Estados miembros del Consejo de Europa; la institucionalización y profesionalización del TEDH a finales del siglo xx; la interpretación evolutiva del Convenio y sus Protocolos; y el crecimiento exponencial, en cuanto a su número y variedad, de los casos resueltos desde finales del siglo xx. Ello ha contribuido a transformar la inicial naturaleza internacionalista del sistema del Convenio en una naturaleza constitucional o cuasi constitucional en el ámbito europeo ${ }^{24}$. Aunque la autoridad de cosa interpretada de la jurisprudencia del TEDH va convirtiéndose con el tiempo en un elemento determinante para las jurisdicciones internas del conjunto de Estados europeos, la garantía normativa de dicha autoridad permanecerá presumiblemente un fenómeno limitado a una minoría de Estados. El art. 10.2 CE y las cláusulas equivalentes en otras Constituciones seguirán sobresaliendo en el panorama del derecho constitucional comparado por juridificar al más alto nivel la vinculación al derecho internacional de los derechos humanos del intérprete de los derechos fundamentales ${ }^{25}$. Esos desarrollos vienen además complementados e impulsados por la entrada en vigor, en agosto de 2018, de un cauce específico de diálogo entre el Tribunal Europeo de Derechos y los órganos judiciales nacionales: en virtud del Protocolo adicional núm. 16, los tribunales nacionales superiores están facultados para dirigirle consultas ${ }^{26}$.

tucional, núm. 30, 2012, pp. 183-224, se trata de "una consecuencia lógica de la imposibilidad de contradicción entre las obligaciones internacionales y las normas internas de un mismo ordenamiento. En definitiva, puede ser conveniente introducir tales cláusulas constitucionales [similares al art. 10.2 CE], básicamente destinadas a orientar a los intérpretes judiciales ordinarios o inferiores, pero es razonable pensar que el intérprete constitucional supremo deba llegar al mismo resultado allí donde esa recomendación no exista, pues está en la naturaleza de las cosas" (p. 205); "donde no existe ese mandato expreso, está implícito o inmanente en la urdimbre que entraña el sistema europeo de garantía y se deriva de las obligaciones internacionales" (p. 221).

24 Vid., entre otros, Christian WALTER, "Die Europäische Menschenrechtskonvention als Konstitutionalisierungsprozess", Zeitschrift für ausländisches öffentliches Recht und Völkerrecht, vol. 59, 1999, pp. 961-983; y Christina M. AKRIVOPOULOU, "The Jurisprudence of the ECtHR as a Common European Constitution", European Review of Public Law/Revue européenne de droit public, vol. 22, núm. 2, 2010, pp. 395-412. En castellano, Javier GARCÍA ROCA, La transformación constitucional del Convenio Europeo de Derechos Humanos, Civitas-Thomson Reuters, Cizur Menor, 2019.

25 En un momento importante para los procesos constitucionales de los Estados del Este y del Centro de Europa, Häberle abogaba por la incorporación, expresa o pretoriana, en todos los Estados constitucionales, del principio de interpretación supranacionalmente conforme de los derechos fundamentales. Vid. Peter HÄBERLE, "Theorieelemente eines allgemeinen juristischen Rezeptionsmodells", Juristenzeitung, 1992, pp. 1033-1043, especialmente 1039 y 1041.

${ }^{26} \mathrm{Al}$ respecto vid. Antonio LÓPEZ CASTILLO y Jörg POLAKIEWICZ, "De la cuestión prejudicial de convencionalidad en marcha”, Teoría y Realidad Constitucional, núm. 44, 2019, pp. 485-500. 


\section{TEORÍA GENERAL DE LA INTERPRETACIÓN CONFORME}

\subsection{Concepto, naturaleza y fundamento}

El principio de interpretación conforme requiere como prius lógico la existencia de dos disposiciones jurídicas: por un lado, la disposición que es objeto de la interpretación conforme ("disposición interpretada") y, por otro, la disposición que debe orientar la interpretación de aquélla ("disposición de interpretación"). Entre el contenido de ambas disposiciones se establece, mediante el principio de interpretación conforme, una relación de naturaleza hermenéutica: de contraste, primero, y de acomodación, después, del programa normativo de la "disposición de interpretación". En suma, el principio de interpretación conforme es un criterio hermenéutico por el cual, de entre los varios sentidos posibles atribuidos a una disposición jurídica ("disposición interpretada"), el intérprete ha de excluir aquel o aquellos que no se acomoden a otra disposición jurídica ("disposición de interpretación”).

La interpretación conforme debe ser diferenciada de las interpretaciones declarativa e integradora. La interpretación declarativa persigue determinar el sentido de una disposición jurídica, y se sirve de los cánones tradicionales de interpretación. Uno de dichos cánones es el criterio sistemático: en el marco de la interpretación declarativa, el conjunto de las disposiciones jurídicas que integran el ordenamiento - y en especial la norma suprema- proporcionan el contexto y conforman el sistema que hay que atender para obtener el sentido de la disposición interpretada. Por su parte, la interpretación integradora se dirige a colmar las lagunas de la ley; los dos procedimientos de la interpretación integradora son la aplicación analógica de la ley y la obtención y aplicación de principios generales del derecho ${ }^{27}$. La interpretación integradora es una actividad creadora de una nueva regla de derecho, mientras que la interpretación conforme conduce a reducir parte del programa normativo de una disposición jurídica: si no reduce su programa normativo, significa que la disposición jurídica interpretada no necesita o no es susceptible de una interpretación conforme.

La disposición de interpretación de la interpretación conforme (p. ej., la Constitución, el tratado internacional sobre derechos humanos o el derecho de la Unión Europea) no deja de ser una disposición jurídica que también puede o debe ser utilizada en las interpretaciones declarativa e integradora. En la medida en que recurren a la Constitución, tanto la interpretación declarativa como la integradora pueden

27 Sobre la diferencia entre interpretación conforme a la Constitución y analogía de acuerdo con la Constitución, vid. Javier JIMÉNEZ CAMPO, "Analogía secundum constitutionem", Revista del Centro de Estudios Constitucionales, núm. 13, 1992, pp. 9-30. El autor señala que "el criterio hermenéutico de la interpretación conforme a la Constitución [...] se ve así prolongado en esta exigencia de la analogía secundum constitutionem" (p. 12). Un supuesto de positivización expresa de la analogía iuris se encuentra en el art. 1 de la Compilación del derecho civil de Cataluña (Decreto Legislativo 1/1984, de 19 de julio): "Para interpretar e integrar esta Compilación y las restantes normas se tomarán en consideración las leyes, las costumbres, la jurisprudencia y la doctrina que constituyen la tradición jurídica catalana, de acuerdo con los principios generales que inspiran el ordenamiento jurídico de Cataluña.” 
ser consideradas de alguna forma interpretaciones "conforme a la Constitución" en un sentido lato ${ }^{28}$. Sin embargo, la consideración de la Constitución desempeña en cada caso una función distinta: determinar el sentido de una disposición legal (interpretación declarativa), integrar las lagunas de la ley (interpretación integradora) o excluir aquellos sentidos posibles de una disposición legal pero incompatibles con la disposición de interpretación (interpretación conforme). La interpretación conforme a la Constitución comparte con la interpretación integradora conforme a la Constitución (en particular al art. $14 \mathrm{CE}$ ) de lagunas discriminatorias ex silentio el de ser "instrumentos que el ordenamiento ofrece a fin de acomodar a la Constitución los dictados de la ley" ${ }^{29}$.

En la interpretación conforme, la disposición de interpretación presenta dos características: determinación y supralegalidad.

- En primer lugar, la disposición de interpretación ha de ser una disposición jurídica cierta y preexistente a la disposición interpretada. La interpretación conforme debe ser diferenciada de aquellos criterios hermenéuticos que, aunque formulados en términos aparentemente imperativos, no utilizan un parámetro de interpretación conforme suficientemente precisado o determinado y, por tanto, no consistente en una disposición jurídica previsible y cierta ${ }^{30}$.

28 Vid. SSTC 167/1991, FJ 3; y 103/1990, FJ 2. Sobre la utilización de la Constitución en las tres interpretaciones (declarativa, integradora y conforme) ya Eduardo GARCÍA DE ENTERRÍA, La Constitución como norma y el Tribunal Constitucional, 3. ${ }^{a}$ ed., Civitas, Madrid, 1983 (reimpresión 2001), p. 102.

29 JIMÉNEZ CAMPO, 1992, p. 27. La cercanía entre la interpretación conforme y la interpretación integradora conforme a la Constitución se pone de manifiesto en los supuestos de disposiciones legales que, de forma discriminatoria, excluyen a una categoría de personas o a ciertos casos del disfrute de una ventaja o derecho. Hay dos posibles entendimientos del problema. Uno consiste en apreciar que la disposición tiene una laguna que se debe integrar con la aplicación directa de la Constitución. También puede entenderse que la disposición aparentemente discriminatoria ex silentio tiene dos posibles significados, el literal y aparentemente querido por el legislador (sólo reconocer la ventaja o derecho a ciertas personas), y el sentido, acorde con la Constitución, de que la disposición contiene una laguna o vacío respecto al disfrute o reconocimiento de la ventaja o derecho por otras personas. Ante el segundo entendimiento existen dos soluciones. De entre los dos sentidos posibles de la disposición aparentemente discriminatoria, el sentido literal quedaría descartado en virtud de la interpretación conforme a la Constitución; posteriormente, la laguna existente se colmaría con la aplicación directa del art. 14 CE. La otra opción consistiría en que el juez ordinario planteara la cuestión de inconstitucionalidad contra la disposición que contiene una exclusión aparentemente discriminatoria. JIMÉNEZ CAMPO aboga por la primera solución cuando se trata de una diferenciación tácita relacionada con un caso o situación típica y por la segunda solución cuando la diferenciación tácita afecta a categorías de personas.

${ }^{30}$ Así, el apartado 4 del art. 52 de la Carta de Derechos Fundamentales de la Unión Europea establece que "en la medida en que la presente Carta reconozca derechos fundamentales resultantes de las tradiciones constitucionales comunes a los Estados miembros, dichos derechos se interpretarán en armonía con las citadas tradiciones". Aunque es dudoso que se trate de un criterio de interpretación conforme en sentido estricto (hay opiniones doctrinales en ambos sentidos), algunos tribunales constitucionales parecen querer impulsar la concepción del art. 52.4 de la Carta como cláusula de interpretación conforme en sentido estricto, probablemente como estrategia para conjurar el efecto unificador de un desarrollo expansivo de los derechos fundamentales por el Tribunal de Justicia o, si se quiere, como 
- En segundo lugar, la disposición de interpretación se caracteriza por su supralegalidad, en virtud de la cual el ordenamiento jurídico le atribuye expresa o implícitamente una especial relevancia en la interpretación y aplicación de las disposiciones legales o infralegales. La supralegalidad no consiste necesariamente en la cualidad de norma de rango jerárquico superior: basta la indisponibilidad de la disposición de interpretación para los órganos constitucionalmente habilitados para adoptar o interpretar la norma interpretada. La emergencia de disposiciones jurídicas vinculantes "supralegales" es un fenómeno relativamente reciente en los sistemas jurídicos; por eso, la interpretación conforme se ha configurado con posterioridad a las interpretaciones declarativa e integradora, que están más arraigadas en la teoría general del derecho. La característica de supralegalidad implica que no existe un principio de interpretación conforme en sentido estricto cuando una disposición de rango legal impone la obligación de interpretar una disposición de rango legal de conformidad con otra disposición de rango legal, normalmente posterior a aquélla: la inaplicación de aquella se sancionará y se combatirá como las demás infracciones del ordenamiento.

La interpretación declarativa precede a la interpretación conforme. El sentido tanto de la disposición de interpretación como de la disposición objeto de la interpretación conforme tiene que ser establecido de forma preliminar, con arreglo a los cánones tradicionales de la interpretación, atendiendo en su caso a las especialidades propias de la disposición o del subsistema normativo al que pertenece ${ }^{31}$. Así, por ejemplo, si la disposición procede del ordenamiento de la Unión Europea, la interpretación debe atender no a reglas hermenéuticas divergentes, pero sí a los matices apreciados por el Tribunal de Justicia de la Unión Europea, en especial al énfasis que se pone en el criterio teleológico ${ }^{32}$. Si la disposición procede de un tratado internacional que cuenta con una jurisdicción que vele por su aplicación e interpretación, como es el caso de las normas del Convenio Europeo de Derechos Humanos, el intérprete interno ha de atender en su caso a la interpretación que de la disposición ha efectuado la jurisdicción internacional ${ }^{33}$. Los sentidos posibles, incluido el sentido o sentidos que se estimarán conformes a la disposición de interpretación, son producto de la interpretación declarativa, utilizando los cánones tradicionales de interpretación. Una vez que se obtienen distintos entendimientos posibles de una disposición

instrumento de coherencia. Vid. Tribunal Constitucional Federal, Sala Segunda, sentencia de 27 de abril de 2021, 2 BvR 206/14 (productos veterinarios), apartados 37 y 39.

31 En este sentido Friedrich MÜLLER y Ralf CHRISTENSEN, Juristische Methodik, Band I: Grundlagen - Öffentliches Recht, 8. ${ }^{a}$ ed., Duncker \& Humblot, Berlín, 2002, pp. 104-105.

32 Vid. Michael POTACS, "Effet utile als Auslegungsgrundsatz", Europarecht, 2009, pp. 465-487; también Giulio ITZCOVICH, "The interpretation of Community Law by the European Court of Justice", German Law Journal, vol. 10, núm. 5, 2009, pp. 537-559.

33 Vid. George LETSAS, A Theory of Interpretation of the European Convention on Human Rights, Oxford University Press, Oxford, 2007. Sobre el contenido de los derechos del Convenio de acuerdo con la jurisprudencia del Tribunal Europeo de Derechos Humanos, vid. William A. SCHABAS, The European Convention on Human Rights. A Commentary, Oxford University Press, Oxford, 2015; Ińaki LASAGABASTER HERRARTE (dir.), Convenio Europeo de Derechos Humanos. Comentario sistemático, 4. ${ }^{a}$ ed., Civitas, Madrid, 2021. 
o un entendimiento con un determinado alcance, la segunda fase — propiamente la interpretación conforme- consiste en contrastar con la disposición de interpretación los sentidos posibles o el alcance posible anteriormente obtenidos de la interpretación "ordinaria": los sentidos posibles que no se acomoden a la disposición de interpretación deben ser descartados y excluidos del programa normativo de la disposición interpretada. En definitiva, el principio de interpretación conforme vincula dos procesos, la interpretación propiamente dicha y el control sobre el programa normativo resultante de esa interpretación ${ }^{34}$.

Existe cierta controversia sobre la relación entre el principio de interpretación conforme (a la Constitución) y los criterios tradicionales de interpretación, recogidos en el ordenamiento español en el art. 3.1 CC. Algunos autores, tanto españoles como extranjeros, suelen relacionar el principio de interpretación conforme a la Constitución con el criterio sistemático de interpretación: ${ }^{35}$ concebido el ordenamiento jurídico como sistema, es lógico que la Constitución ejerza una eficacia orientadora y hermenéutica de primer orden sobre cada elemento del sistema; de esta forma, la interpretación conforme a la Constitución se confundiría con el principio de unidad del ordenamiento.

La caracterización de la interpretación conforme como subespecie del criterio sistemático de interpretación se enfrenta, no obstante, a dos objeciones. Por un lado, la interpretación conforme conduce a desechar uno o varios sentidos posibles como inconciliables con la disposición de interpretación y, por tanto, parte del programa normativo posible de la disposición interpretada es en último término repudiado como inconstitucional, incompatible con la disposición de derecho de la Unión Europea o contradictoria con la disposición internacional de derechos humanos (según la naturaleza de la disposición de interpretación a la que se acuda en cada caso); ello equivale a una declaración parcial de nulidad de su programa normativo, sin que al mismo tiempo se recorte el texto de la disposición. En otros términos, la Constitución o la disposición de interpretación correspondiente cumplen dos funciones diferentes: en el marco de la interpretación sistemática contribuye como el resto del ordenamiento a fijar los sentidos posibles de la disposición en cuestión; en el marco de la interpretación conforme ejerce una función de control sobre esos sentidos posibles ${ }^{36}$.

Por otro lado, la referida caracterización de la interpretación conforme como subespecie del criterio sistemático de interpretación se extrae de una de sus variantes,

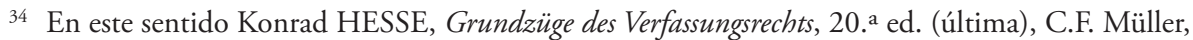
Heidelberg, 1999, p. 31: "Im Rahmen verfassungskonformer Auslegung sind Verfassungsnormen also nicht nur ,Prüfungsnormen', sondern auch ,Sachnormen 'zur Inhaltsbestimmung einfacher Gesetze”; igualmente MÜLLER y CHRISTENSEN, 2002, p. 104: "Der Grundsatz verbindet somit Normtextauslegung mit Normenkontrolle".

35 Vid., p. ej., Manuel CALVO GARCÍA (ed.), Interpretación y argumentación juridica. Trabajos del Seminario de Metodología Juridica (volumen 1), PUZ, Zaragoza, 1995, pp. 42, 168.

36 Andreas VOSSKUHLE, “Theorie und Praxis der verfassungskonformen Auslegung von Gesetzen durch Fachgerichte - Kritische Bestandaufnahme und Versuch einer Neubestimmung", Archiv des öffentlichen Rechts, vol. 125, 2000, pp. 177-201, esp. 181-182. 
sin duda la más importante y conocida en el derecho comparado, pero variante al fin y al cabo, el principio de interpretación conforme a la Constitución, y no se puede extender a aquellas otras variantes de interpretación conforme que recurren a disposiciones - como la disposición europea o las disposiciones de los tratados internacionales sobre derechos humanos- que no disponen de supremacía (Geltungsvorrang) sobre la disposición interpretada, sino que solo gozan de aplicación preferente (Anwendungsvorrang) ${ }^{37}$.

Para otros autores, en cambio, el principio de interpretación conforme (a la Constitución) no es un criterio de interpretación (como el literal, el lógico, el sistemático, el histórico, etc.), sino un criterio sobre la interpretación ${ }^{38}$, o mejor, una "directriz de preferencia" ${ }^{39}$ o una "regla interpretativa prioritaria" (interpretatorische Vorrangsregel) ${ }^{40}$. La consideración de la interpretación conforme como "regla interpretativa prioritaria” es la que, a nuestro juicio, parece más correcta.

37 Esta distinción (supremacía-jerarquía vs. primacía-aplicación) desempeñó en la Declaración 1/2004 del Tribunal Constitucional (FJ 4) un papel crucial para fundamentar la compatibilidad del principio de primacía del derecho de la Unión Europea con la (supremacía de la) Constitución española. La distinción entre Geltungsvorrang y Anwendungsvorrang procede de la dogmática alemana: vid., por todas, BVerfGE 73, 339 (375), Solange II. Como señala CANARIS, la interpretación conforme a la Constitución se fundamenta en último término en la cualidad de la Constitución como lex superior, mientras que la interpretación conforme a las directivas no se puede basar en ese fundamento, cuando menos no de forma inmediata; con todo, después atenúa las diferencias y reconoce que la directiva aunque no sea lex (lo será cuando sea traspuesta), sí es en cierto sentido superior a la norma interna, ya que participa de la primacía del derecho de la Unión Europea. Vid. Claus-Wilhelm CANARIS, "Die richtlinienkonforme Auslegung und Rechtsfortbildung im System der juristischen Methodenlehre", en Helmut KOZIOL y Peter RUMMEL (eds.), Im Dienste der Gerechtigkeit - Festschrift für Franz Bydlinski, Springer, Viena/Nueva York, 2002, pp. 47-103 (pp. 53, 66 y 69).

38 Javier JIMÉNEZ CAMPO, "Interpretación conforme a la Constitución", en M. ARAGÓN REYES (coord.), Temas básicos de Derecho Constitucional, tomo I, Civitas, Madrid, 2001, p. 61.

39 Wróblewski distingue entre directivas interpretativas de primer grado (determinan cómo el intérprete debe atribuir significado a una disposición jurídica, teniendo en cuenta los contextos relevantes, p. ej., lingüístico, sistemático y funcional) y directivas interpretativas de preferencia (determinan cómo el intérprete debe elegir entre los diferentes resultados de la aplicación de las directivas de primer grado). Vid. Jerzy WRÓBLEWSKI, "An outline of a general theory of legal interpretation and constitutional interpretation", Acta Universitatis Lodziensis, Folia Iuridica 32, 1987, pp. 33-89, esp. 42 ss. El autor señala que las directivas de preferencia, por lo general, no han sido tan ampliamente analizadas en la bibliografía jurídica como las directivas de primer grado, y a menudo no son explícitamente diferenciadas con respecto a las primeras (p. 53). En su trabajo, la interpretación conforme a la Constitución (o a otro principio jurídico extrasistémico) se corresponde con una directiva interpretativa de primer grado (DI1-10). Debe subrayarse que Wróblewski analiza la interpretación constitucional desde la perspectiva de la teoría general de la interpretación y no desde el punto de vista del derecho constitucional. También acoge la distinción entre directivas de primer y segundo grado: Juan IGARTUA SALABERRIA, Teoría Analitica del derecho (La interpretación de la Ley), Ońate, IVAP, 1994, pp. 83-84.

40 CANARIS, 2002, pp. 66-79; sobre la autonomía de la interpretación conforme dentro del sistema de la metodología jurídica, ibidem, pp. 79-81. Este autor distingue entre criterios de interpretación y reglas de precedencia interpretativa. Concibe a los primeros como "principios" y a las segundas como "reglas" en el sentido de la teoría de Alexy. En el mismo sentido MÜLLER y CHRISTENSEN, 2002, p. 105, hablan de una regla de preferencia (Vorzugsregel) y rechazan que el principio de interpretación conforme pertenezca a los criterios tradicionales de interpretación, incluido el criterio sistemático. 
La doctrina sobre la interpretación jurídica concibe los cánones tradicionales de interpretación como criterios no excluyentes que no conforman un sistema jerarquizado, lo cual no impide la elaboración jurisprudencial y doctrinal de reglas específicas de preferencia, que determinan que un criterio o punto de vista prevalezca de forma general en una determinada situación ${ }^{41}$. La regulación legal de los criterios y reglas interpretativas llevada a cabo en algunos ordenamientos (Suiza, Austria, España, etc.) tiene como finalidad conseguir cierta uniformidad en la práctica jurisdiccional. Así, para la doctrina civilista espańola, el art. 3.1 CC es vinculante, no en cuanto elenco excluyente o inexcusable de cánones interpretativos, sino por la prioridad otorgada, en la labor hermenéutica, al espíritu y finalidad de las normas; los cánones mencionados tendrían a este respecto carácter auxiliar ${ }^{42}$.

La interpretación conforme no se confunde con los criterios tradicionales de interpretación, sino que, por su carácter de regla preferente se impone al juego ordinario y ponderado de dichos criterios ${ }^{43}$. La interpretación conforme proporciona una indicación normativa vinculante: obliga a descartar, de entre los sentidos posibles de la disposición jurídica obtenidos de la aplicación de los cánones interpretativos, aquel sentido o sentidos que no se acomoden a las disposiciones de interpretación conforme establecidas (la Constitución, los tratados internacionales sobre derechos humanos o el derecho de la Unión Europea).

En suma, al igual que las reglas de interpretación, la interpretación conforme contribuye a determinar el sentido de la disposición jurídica aplicable, esto es, a construir la norma aplicable. Por esta razón, la doctrina mayoritaria ha situado la interpretación conforme en una zona cercana a las reglas de interpretación; para algunos autores, incluso, la interpretación conforme es una regla de interpretación más. No obstante, la interpretación conforme es una regla vinculante y opera de forma disyuntiva, como las reglas de aplicación: un sentido posible de la disposición jurídica es disconforme o no, de la misma forma que una disposición jurídica es o no aplicable. En cierto sentido podría decirse que la interpretación conforme es una regla de inaplicación (o de aplicación negativa): no dice qué hay que aplicar sino qué no hay que aplicar. Pero es una regla de (in-)aplicación sin autonomía propia y, como se verá cuando se analicen los límites de la interpretación conforme, requiere que exista una disposición jurídica aplicable susceptible de una interpretación conforme: en ausencia de disposición jurídicas aplicables al caso, no puede resolverse un supuesto fáctico con una regla negativa.

${ }^{41}$ CANARIS, 2002, pp. 58, 65, 79. Vid. también Karl LARENZ, Methodenlehre der Rechtswissenschaft, 2. a ed., Springer, Berlín, 1992 (verkürzte Studienausgabe de la 6. a y última edición de su obra, 1991), p. 228: "Die Auslegungsmethoden unterliegen ... keiner starren Rangfolge".

${ }_{42}$ Miguel Ángel PÉREZ ÁLVAREZ, Interpretación y jurisprudencia. Estudio del artículo 3.1 del Código Civil, Aranzadi, Pamplona, 1994, pp. 130 ss.

43 CANARIS, 2002, pp. 70, 79. En el mismo sentido Ricardo ALONSO GARCÍA, "La interpretación del Derecho de los Estados conforme al Derecho Comunitario: las exigencias y límites de un nuevo criterio hermenéutico", Revista Española de Derecho Europeo, núm. 28, 2008, pp. 397-399. 
En cada modalidad de interpretación conforme el ordenamiento jurídico asume una regla interpretativa prioritaria. Dada la pluralidad de reglas de preferencia, cabe la posibilidad de una colisión entre ellas. La interpretación conforme al derecho de la Unión Europea prevalece en principio sobre la interpretación conforme a la Constitución. No obstante, antes de optar sin más por aquella es necesario procurar interpretar la Constitución de conformidad con el derecho de la Unión, para de esta forma intentar obtener una interpretación de la disposición interpretada compatible al mismo tiempo con las dos disposiciones de interpretación existentes. Si no es posible interpretar la Constitución de conformidad con el derecho de la Unión Europea, el poder de reforma debe intervenir para modificar la Constitución ${ }^{44}$.

\subsection{Función}

El principio de interpretación conforme cumple dos funciones: la máxima realización de la disposición de interpretación, así como la reorientación y la armonización de las disposiciones jurídicas quizá susceptibles de un entendimiento distinto e inconciliable con la disposición de interpretación. Ambas funciones se muestran en los procesos de aplicación y de enjuiciamiento o de apreciación de la validez de disposiciones jurídicas.

Por un lado, el principio de interpretación conforme es justamente una de las técnicas mediante la cual los modernos ordenamientos jurídicos procuran la máxima realización de la Constitución, o bien la máxima coordinación con el derecho internacional de los derechos humanos, o bien la máxima realización de las normas de una organización supranacional como la Unión Europea. Como señaló el Tribunal Supremo español, "la naturaleza normativa y no meramente programática de la Constitución reclama una interpretación de sus preceptos que aspire a lograr el máximo reconocimiento de su fuerza vinculante" ${ }^{45}$.

Por otro lado, el principio de interpretación conforme cumple también una función armonizadora y reorientadora de disposiciones jurídicas y, al mismo tiempo, integradora de vacíos normativos, de la falta o insuficiencia de un cuerpo de doctrina constitucional sobre el ámbito de protección de las disposiciones iusfundamentales o de déficits de trasposición. El principio de interpretación conforme a la Constitución hizo posible la reorientación de las disposiciones jurídicas preexistentes en sentido constitucional y propició tanto la continuidad del ordenamiento como la evitación de los vacíos normativos que se hubieran seguido de la eventual declaración de inconstitucionalidad de disposiciones susceptibles de un entendimiento acomodado a la Constitución ${ }^{46}$. El principio de interpretación conforme a los tratados interna-

44 CANARIS, 2002, p. 80.

45 STS 4/12/1990, Ar. 9721.

46 JIMÉNEZ CAMPO, 1992, p. 62. La idea está también presente en la obra de HESSE, 1999, p. 31, pese al tiempo transcurrido desde la aprobación de la Ley Fundamental de Bonn. 
cionales sobre derechos humanos (art. 10.2 CE) propició un llenado y un anclaje mínimos del ámbito de protección de los derechos fundamentales constitucionales ${ }^{47}$.

La función integradora del principio de interpretación conforme alcanza una nueva dimensión cuando se predica respecto a las directivas de la Unión Europea. El principio de interpretación conforme a las directivas de la Unión Europea no solo propicia la unidad y la máxima realización del derecho de la Unión, a través de la compatibilización del programa normativo de las disposiciones jurídicas internas con los fines perseguidos por las directivas ${ }^{48}$. También suple los vacíos, carencias y defectos detectados en la transposición de las directivas al ordenamiento interno ${ }^{49}$. Esa intensa función correctora del principio de interpretación conforme a las directivas europeas se fundamenta en el principio de cooperación leal del art. 4.3 del Tratado de la Unión Europea. El Tribunal de Justicia de la Unión Europea se apoya en este principio para exigir a las autoridades estatales, tanto judiciales como administrativas, que hagan "todo lo posible" y movilicen todos los recursos y mecanismos jurídicos disponibles en el ordenamiento interno, al servicio de la efectividad del derecho de la Unión y del cumplimiento de los fines perseguidos por las directivas. Además, el mandato de interpretación conforme al derecho de la Unión no se limita a las disposiciones internas adoptadas específicamente para transponer o aplicar ese derecho: requiere que "la jurisdicción nacional tome en consideración el conjunto del derecho nacional para apreciar en qué medida éste puede recibir una aplicación tal que no conduzca a un resultado contrario al contemplado por el derecho comunitario" ${ }^{50}$.

${ }^{47}$ La temprana utilización queda atestiguada en la jurisprudencia constitucional: SSTC 42/1982, FJ 3; y 62/1982, FJ 2.

48 Debe tenerse en cuenta que, en no pocas ocasiones, las normas europeas provocan "rupturas sistémicas" en los sectores afectados. Para una reflexión, más bien defensiva, sobre los desafíos para la "unidad del ordenamiento" desde la perspectiva de la legislación civil nacional penetrada por normas europeas puede consultarse Jens $\mathrm{KOCH}$, "Die Einheit der nationalen Rechtsordnung und die europäische Privatrechtsangleichung", Juristen-Zeitung, núm. 6, 2006, pp. 277-284: sostiene que las "rupturas sistémicas" originadas por el derecho de la Unión confieren nueva relevancia dogmática al postulado de la "unidad del ordenamiento". La cuestión es si esa unidad debe reconstituirse desde la tradición estatal o a partir del derecho de la Unión. Justamente, el principio de interpretación conforme a las directivas contribuye a compatibilizar el contenido de regulaciones estatales preexistentes con las lógicas procedentes del derecho de la Unión.

49 ALONSO GARCÍA, 2008, pp. 385 y sigs., subraya las diferencias de la interpretación del derecho de los Estados conforme al derecho comunitario respecto a la interpretación del derecho interno conforme a la Constitución. En particular sostiene que el principio de conservación del ordenamiento jurídico "es un principio ajeno a la aplicación del principio de interpretación de los derechos nacionales conforme al derecho comunitario" (p. 390), pero reconoce que la interpretación conforme, al operar en ausencia de normas europeas con eficacia directa, es "la única vía que permitiría la «armonización" europea de la legislación nacional” (p. 394). A mi modo de ver, la función consiste en la reorientación y armonización de normas preexistentes e integración de vacíos e insuficiencias normativos, y la consecuencia es la conservación de las normas preexistentes, con un contenido armonizado a la norma de interpretación conforme. Sin duda la idea de conservación y de continuidad del ordenamiento es jurídica y políticamente muy importante en los supuestos de ruptura o cambio del orden constitucional, y por eso se la considera como "función" de la interpretación conforme a la Constitución.

50 Sentencia del Tribunal de Justicia de 5 de octubre de 2004, as. C-397/01, Bernhard Pfeiffer y otros/Deutsches Rotes Kreuz, p. I-8835, apdo. 116. 
A diferencia de las disposiciones preconstitucionales, la conservación de las disposiciones jurídicas postconstitucionales no tiene como finalidad inmediata garantizar la continuidad del ordenamiento como tal, sino garantizar la prioridad del legislador en la concretización de la Constitución. El principio de interpretación conforme expresa así circunspección hacia el legislador democrático ${ }^{51}$. Ahora bien, este planteamiento es correcto cuando el juicio de constitucionalidad versa sobre la constitucionalidad sustancial de la ley, pero no cuando se dilucida si ha existido o no invasión competencial: en este supuesto existen dos legisladores democráticos, y no puede haber circunspección hacia uno en detrimento del otro ${ }^{52}$.

Las diversas variantes de interpretación conforme cumplen funciones equivalentes. La diferencia estriba en quién tiene la última palabra sobre la adecuación de la interpretación conforme, que, en principio, corresponde a cualquier órgano jurisdiccional y administrativo ${ }^{53}$. Así, en el ordenamiento jurídico español el Tribunal Constitucional tiene la última palabra en relación con dos de las variantes, la interpretación del ordenamiento jurídico conforme a la Constitución y de los derechos fundamentales conforme a los tratados internacionales sobre derechos humanos; pues, o bien la disposición interpretada o bien la disposición de interpretación coinciden con la Constitución. La tercera variante, en cambio, discurre fuera del plano de la constitucionalidad, y las funciones se reparten de la siguiente forma: el Tribunal de Justicia tiene la última palabra respecto a la interpretación definitiva del derecho de la Unión Europea, y el Tribunal Supremo la tiene en cuanto a la correcta utilización de los criterios y las reglas de interpretación previstos en el ordenamiento jurídico interno, incluida la aplicación de la regla prioritaria de la interpretación conforme al derecho de la Unión Europea.

La función constitucional del sujeto que acude a la interpretación conforme condiciona su significado. Así, mientras sobre el juez constitucional pende el mandato constitucional dirigido a evitar la declaración de inconstitucionalidad de la ley, para el juez ordinario puede constituir una obligación o bien una alternativa al planteamiento de la cuestión de inconstitucionalidad. El grado efectivo de realización de la interpretación conforme por los órganos judiciales dependerá del nivel de exigencia y rigor aplicado por la jurisdicción constitucional a la hora de admitir o inadmitir la cuestión de inconstitucionalidad ${ }^{54}$. La situación es parecida en el ámbito del derecho de la Unión Europea. Si bien el Tribunal de Justicia tiene el monopolio de la declaración de invalidez de las disposiciones de derecho de la Unión, los jueces nacionales como jueces ordinarios de la Unión Europea disponen de la cuestión prejudicial del art. 267 TFUE, que sirve tanto para el control de validez como para la interpreta-

51 HESSE, 1999, p. 32; MÜLLER y CHRISTENSEN, 2002, p. 105.

52 El tema ha sido abordado por LÓPEZ BOFILL, 2004, pp. 353-381.

53 Para las tres modalidades de interpretación conforme diferenciadas en este trabajo y su asunción por la Administración española, puede verse José María RODRÍGUEZ DE SANTIAGO, Metodología del Derecho administrativo. Reglas de racionalidad para la adopción y el control de la decisión administrativa, Marcial Pons, Madrid, 2016, pp. 77-92.

${ }^{54}$ LÓPEZ BOFILL, 2004, pp. 116-117 en referencia al ordenamiento constitucional alemán. 
ción de los actos jurídicos europeos. Los jueces ordinarios cuentan, en suma, con un mecanismo de reenvío específico para las dudas de interpretación del derecho de la Unión Europea que se suscitan en los litigios sometidos a su conocimiento, sin que la posibilidad de una interpretación conforme de la disposición europea les impida el reenvío al Tribunal de Justicia o sea un obstáculo para la admisión a trámite de la cuestión prejudicial promovida.

\subsection{Modalidades}

El ordenamiento jurídico español conoce al menos tres modalidades de interpretación conforme: la interpretación conforme a la Constitución (art. 5 LOPJ), la interpretación conforme a los tratados internacionales sobre derechos humanos (art. 10.2 CE) ${ }^{55}$, y la interpretación conforme al derecho de la Unión Europea, especialmente conforme a las directivas. Esta última modalidad de interpretación conforme, creada por el Tribunal de Justicia ${ }^{56}$, no fue mencionada expresamente por el derecho interno hasta $2015^{57}$.

Característica básica del principio de interpretación conforme es su imperatividad. El principio de interpretación conforme no es un mero punto de vista a considerar en el marco de la interpretación de las disposiciones jurídicas, sino un mandato

55 Sobre la interpretación conforme a los tratados internacionales sobre derechos humanos en España (ex art. 10.2 CE) vid., por todos, SÁIZ ARNÁIZ, 1999; Argelia QUERALT JIMÉNEZ, La interpretación de los derechos: del Tribunal de Estrasburgo al Tribunal Constitucional, CEPC, Madrid, 2008; Xabier ARZOZ SANTISTEBAN, La concretización y actualización de los derechos fundamentales, CEPC, Madrid, 2014, pp. 159-262; Alejandro SÁIZ ARNÁIZ, "Artículo 10.2. La interpretación de los derechos fundamentales y los tratados internacionales sobre derechos humanos", en RODRÍGUEZ PINEERO Y BRAVO FERRER, M. y CASAS BAAMONDE, M. E. (dirs.), Comentarios a la Constitución española. XL Aniversario de la Constitución, BOE-Fundación Wolters Kluwer España-Ministerio de Justicia-Tribunal Constitucional, 2018, pp. 230-254; y Argelia QUERALT JIMÉNEZ, "Artículo 10.2", en Pablo PÉREZ TREMPS y Alejandro SÁIZ ARNÁIZ (dirs.), Carmen MONTESINOS PADILLA (coord.), Comentario a la Constitución Española: 40 aniversario 1978-2018: Libro-homenaje a Luis López Guerra, vol. 1, 2018, pp. 277-286.

56 Sentencia del Tribunal de Justicia de 13 de noviembre de 1990, Marleasing SA, Rec. I-4156, apartado 8. Al respecto vid. Winfried BRECHMANN, Die richtlinienkonforme Auslegung, Beck, Múnich, 1994; Georg RESS, "Die richtlinienkonforme 'Interpretation' innerstaatlichen Rechts", Die Öffentliche Verwaltung, núm. 12, vol. 47, 1994, pp. 489-497; Sacha PRECHAL, Directives in EC Law, 2. a ed., Oxford, Oxford University Press, 2005, pp. 180-215; ALONSO GARCÍA, 2008; Xabier ARZOZ SANTISTEBAN, "Interpretación conforme", en Juan Alfonso Santamaría Pastor (dir.), Los principios jurídicos del Derecho administrativo, La Ley, Madrid, 2010, pp. 647-658; Ricardo ALONSO GARCÍA, "La interpretación del Derecho nacional en función de la entrada en vigor de las Directivas y de su fecha límite de transposición (o su trasposición anticipada)", Revista Española de Derecho Europeo, núm. 64, 2017, pp. 13-24.

$57 \mathrm{El}$ art. 4 bis LOPJ, añadido por el art. único.2 de la Ley Orgánica 7/2015, de 21 de julio, establece lo siguiente: "1. Los Jueces y Tribunales aplicarán el derecho de la Unión Europea de conformidad con la jurisprudencia del Tribunal de Justicia de la Unión Europea.- 2. Cuando los Tribunales decidan plantear una cuestión prejudicial europea lo harán de conformidad con la jurisprudencia del Tribunal de Justicia de la Unión Europea y, en todo caso, mediante auto, previa audiencia de las partes." 
jurídico dirigido en principio a todos los aplicadores del derecho ${ }^{58}$. Recientemente, la jurisprudencia constitucional española ha calificado el criterio hermenéutico del art. 10.2 CE como "pauta interpretativa indisponible" 59 . En consecuencia, el principio de interpretación conforme debe ser distinguido de aquellas indicaciones, recomendaciones o pautas interpretativas desprovistas de obligatoriedad, propuestas doctrinalmente o utilizadas jurisprudencialmente.

El carácter imperativo de la interpretación conforme como criterio hermenéutico es, naturalmente, consecuencia de una disposición jurídica. Toda manifestación del principio se ha de fundamentar en una norma expresa o implícita de rango constitucional ${ }^{60}$. Ello no obsta para que disposiciones jurídicas subconstitucionales reconozcan con eficacia declarativa el principio de interpretación conforme deducido de la Constitución.

El número de subprincipios de interpretación conforme puede aumentar en el futuro, y es posible que lo haga, como expresión de la interacción creciente entre los sistemas jurídicos. En cualquier caso, siempre requerirá una fundamentación jurídica adecuada.

La interpretación conforme a los tratados internacionales ratificados por España, los cuales, debidamente celebrados y publicados en el Boletin Oficial del Estado, forman parte del ordenamiento interno (art. $96 \mathrm{CE}$ ), puede ser una variante adicional ${ }^{61}$. Su relevancia reside, claro está, en aquellos tratados internacionales que no se refieren a los derechos humanos, que ya están incluidos en el mandato de interpretación conforme consagrado por el art. 10.2 CE.

En el ordenamiento español, la Carta Europea de la Autonomía Local, tratado internacional elaborado bajo los auspicios del Consejo de Europa, ha merecido una apreciación y valoración doctrinal y jurisprudencial crecientemente positiva a efectos

58 JIMÉNEZ CAMPO, 2001, p. 61 ("un imperativo jurídico-constitucional para todos los aplicadores del derecho, siempre y cuando [...] resulte factible"). Según la doctrina dominante, la interpretación integradora es así mismo obligatoria para los órganos judiciales: vid. art. 4.1 CC. La interpretación declarativa es también obligada, no solo desde el punto de vista jurídico, sino desde una perspectiva puramente lógica, con independencia de que esté o no regulada: es necesario determinar el sentido de la norma para apreciar si es o no aplicable al caso. El problema de la interpretación declarativa estriba en el carácter vinculante o no, y tasado o no, de los criterios de interpretación previstos legalmente.

59 STC 23/2020, FJ 6.

${ }^{60}$ Así, con anterioridad a la aprobación del art. 5 LOPJ, GARCÍA DE ENTERRÍA, 1983, p. 102, escribía que la interpretación conforme a la Constitución se fundamentaba en una norma implícita.

${ }^{61}$ En España no hay una disposición constitucional que determine si el derecho internacional general forma parte del ordenamiento español. Sobre la posibilidad de un principio de interpretación de la Constitución conforme al derecho internacional vid. Rudolf BERNHARDT, "Völkerrechtliche Auslegung der Verfassung? Verfassungskonforme Auslegung völkerrechtlicher Verträge”, en Hans-Joachim CREMER, Thomas GIEGERICH, Dagmar RICHTER y Andreas ZIMMERMANN (eds.), Tradition und Weltoffentheit des Rechts - Festschrift für Helmut Steinberger, tomo I, Springer, Berlín, 2002, pp. 391400. Vid. también Gerrit BETLEM y André NOLLKAEMPER, "Giving effect to public international law and European Community law before domestic courts. A comparative analysis of the practice of consistent interpretation", European Journal of International Law, vol. 14, núm. 3, 2003, pp. 569-589. 
de la interpretación del ordenamiento interno de régimen local. La jurisprudencia del Tribunal Supremo expresamente ha señalado que la Carta constituye "un importante instrumento de interpretación del principio de la autonomía local que consagra la Constitución" 62. Por lo general, el Tribunal Supremo sitúa dicha interpretación metodológicamente en el marco del art. 3.1 CC y la conecta al postulado de que la interpretación se llevará a cabo "de acuerdo con la realidad social de los tiempos en que las normas deban aplicarse" ${ }^{63}$. No obstante, en ocasiones no duda en interpretar las propias disposiciones constitucionales de la forma más compatible con lo establecido en la Carta Europea de la Autonomía Local ${ }^{64}$.

En la actualidad, existen elementos para construir un principio de interpretación conforme a los tratados internacionales ratificados por España. Una tímida codificación del principio de interpretación conforme a los tratados internacionales se acoge en el art. 35.4 de la Ley 25/2014, de 27 de noviembre, de Tratados y otros Acuerdos Internacionales, que dispone de que "las disposiciones dictadas en ejecución de tratados internacionales en los que España sea parte se interpretarán de conformidad con el tratado que desarrollan". El tenor literal del precepto parece excluir la interpretación conforme cuando no se hubieran aprobado disposiciones específicas para la ejecución del tratado internacional: este sería el caso de la citada Carta Europea de la Autonomía Local. No obstante, esa exclusión no sería lógica si la razón de la inexistencia de disposiciones específicas de ejecución es que el legislador consideró que la legislación interna garantizaba un cumplimiento suficiente del tratado internacional. El límite estribaría únicamente en si existen disposiciones internas que puedan compatibilizarse con lo establecido en el tratado internacional.

En cualquier caso, un principio general de interpretación conforme a los tratados internacionales se puede deducir de las reglas que rigen las relaciones entre normas internas e internacionales en el sistema de fuentes. Aunque las relaciones entre ley y tratado internacional no han sido suficientemente aclaradas y se han defendido diversas soluciones basadas en los principios de jerarquía o de competencia o en otras consideraciones, la doctrina mayoritaria abogaba por que la contradicción entre un tratado internacional que forma parte del ordenamiento interno (arts. $96 \mathrm{CE}$ y art. 1.5 CC) y una ley adoptada posteriormente fuera resuelta en la jurisdicción

62 SSTS 29/09/2003, Ar. 6487; 25/05/2004, Ar. 4036; 20/12/2007, Ar. 4887/2008; 30/01/2008, Ar. 1934. Vid. al respecto José Manuel BANDRÉS SÁNCHEZ-CRUZAT, "La Carta Europea de la Autonomía Local en la jurisprudencia del Tribunal Supremo”, Quaderns de Dret Local, núm. 20, junio 2009, pp. 7-22.

${ }^{63}$ Vid. SSTS 29/09/2003, Ar. 6487, y 30/01/2008, Ar. 1934. En el fundamento quinto de esta última se dice al respecto: "Una interpretación de este tipo no hace sino cumplir la finalidad que atribuye a la jurisprudencia de este Tribunal Supremo el Título Preliminar del Código Civil, cuando en su artículo 1.6 dispone que completará el ordenamiento jurídico y en el artículo 3.1 que la interpretación a realizar se llevará a cabo de acuerdo con los antecedentes legislativos y la realidad social de los tiempos en que las normas deban aplicarse".

64 Vid., por ejemplo, las SSTS 29/09/2003, Ar. 6487, 25/0/2004, Ar. 4036, 20/12/2007, Ar. 4887/2008, y 9/12/2009, JUR 2010\16387. 
ordinaria con la inaplicabilidad de la segunda ${ }^{65}$. En 2018 el Tribunal Constitucional sancionó formalmente esa interpretación, en consonancia con pronunciamientos anteriores ${ }^{66}$. Pues bien, la contrapartida de ese poder de inaplicación debe ser la obligación de interpretación conforme, pues quien está facultado para inaplicar una disposición de rango legal por incompatibilidad con una disposición superior debe estar a fortiori obligado a procurar su conservación, siempre que ello sea posible.

\subsection{Límites}

La interpretación conforme tiene el mismo límite infranqueable que la aplicación, interpretación e integración creadora de lagunas por los órganos jurisdiccionales: el texto y la finalidad de la disposición legal que se interpreta. Por un lado, el juez no puede interpretar contra legem. La interpretación conforme debe detenerse allí donde exista una contradicción insalvable entre la disposición interpretada y la disposición de interpretación. Supuesta la supremacía, primacía o mayor rango de la disposición de interpretación y una vez apreciada esa contradicción insalvable, solo puede ser resuelta mediante la declaración de inconstitucionalidad o incompatibilidad de la disposición interpretada por quien tenga competencia para esa declaración y mediante la aplicación de las consecuencias correspondientes, la expulsión del ordenamiento jurídico o bien su inaplicación. En otros términos, la interpretación conforme no tiene carácter autónomo ni absoluto: no arrincona las reglas tradicionales de interpretación ${ }^{67}$.

Por otro lado, la disposición interpretada o la laguna de regulación debe ser susceptible de una interpretación conforme ${ }^{68}$. La disposición interpretada debe dejar espacio para la interpretación conforme, bien porque contenga una cláusula general

${ }^{65}$ Vid., por todos, Ignacio DE OTTO, Derecho constitucional. Sistema de fuentes, 2. ${ }^{\text {a }}$ ed. (y última), Ariel, Barcelona, 1988, 4. a reimpresión de 1995, p. 126: la relación entre el tratado y las leyes posteriores se articula mediante reglas de aplicación: la ley contraria a un tratado en vigor no es nula, pero el tratado prevalece sobre ella. En esencia, la diferenciación entre validez (superior) y aplicación (prioritaria) ha sido asumido por el Tribunal Constitucional en su Declaración 1/2004, relativa al Tratado por el que se establece una Constitución para Europa.

66 " [...] en aplicación de la prescripción contenida en el artículo $96 \mathrm{CE}$, cualquier juez ordinario puede desplazar la aplicación de una norma interna con rango de ley para aplicar de modo preferente la disposición contenida en un tratado internacional, sin que de tal desplazamiento derive la expulsión de la norma interna del ordenamiento, como resulta obvio, sino su mera inaplicación al caso concreto" (STC 140/2018, FJ 6). Al respecto puede verse Ricardo ALONSO GARCÍA, "El control de convencionalidad: cinco interrogantes", Revista Española de Derecho Constitucional, núm. 119, 2020, pp. 13-51. En cuanto a las resoluciones previas pueden contrastarse las SSTC 28/1991, FJ 5; 207/2013, FJ 4; y 270/2015, FJ 6.

67 Vid. para una crítica en este sentido respecto a cierta jurisprudencia del Tribunal Supremo Contencioso-Administrativo Federal alemán en materia de funcionarios: Reinhard H. RIEGER, "Grenzen verfassungskonformer Auslegung", Neue Zeitschrift für Verwaltungsrecht, 2003, pp. 17-22. El voto particular del magistrado Pérez Tremps a la STC 17/2013 invocó dicha sentencia y su criterio.

${ }_{68} \mathrm{El}$ problema específico de la integración de lagunas y la interpretación conforme no puede ser abordado en este trabajo. Para un análisis de la relevancia de la interpretación conforme para la integra- 
o un concepto jurídico indeterminado bien porque, aunque cuente con un supuesto de hecho preciso, los criterios tradicionales de interpretación apuntan en direcciones opuestas. En caso contrario, no le corresponde al órgano jurisdiccional completar o corregir el programa normativo de la disposición, sino que debe ser el legislador quien subsane la incompatibilidad de la regulación legal o su inexistencia. La interpretación conforme no faculta para remediar cualesquiera deficiencias o déficits de la disposición interpretada y, por tanto, no puede reemplazar la intervención del legislador, cuando esta sea necesaria ${ }^{69}$. Esto no es tanto un límite específico impuesto por la metodología jurídica cuanto un límite derivado del propio derecho positivo que impone el respeto de las funciones y de las competencias atribuidas a cada poder del Estado ${ }^{70}$.

\section{LA INTERPRETACIÓN CONFORME EN EL MARCO DE LOS CONTROLES SOBRE LA LEY}

\subsection{De la teoría a la realidad: la asimétrica práctica de la interpretación conforme a la Constitución}

La relevancia del principio de interpretación conforme a la Constitución, en el momento de la aprobación de esta, en 1978, constituye un lugar común en la doctrina española ${ }^{71}$. El Tribunal Constitucional afirmó tempranamente el principio, señalando que la interpretación conforme era una "consecuencia obligada de su doble carácter de Ley posterior y de Ley superior, y responde además a un criterio de prudencia que aconseja evitar que se produzcan lagunas en el ordenamiento" ${ }^{72}$. La doctrina mayoritaria fundamenta el principio de interpretación conforme a la Constitución bien en el carácter de lex superior de la Constitución o principio de constitucionalidad ex art. 9.1 $\mathrm{CE}^{73}$, bien en el principio de unidad del ordenamiento ${ }^{74}$. Si aceptamos con Hans Kelsen que "todas las normas cuya validez puede ser referida a una y la misma norma fundamental constituyen un orden o sistema normativo" y

ción de lagunas en el ordenamiento (p. ej., las surgidas por la falta de transposición de una directiva) desde la perspectiva de la metodología jurídica alemana vid. CANARIS, 2002, pp. 81-90.

69 El Tribunal Constitucional Federal alemán ha señalado que la interpretación conforme no puede conducir a colmar la indeterminación de una ley que regula una medida restrictiva de derechos fundamentales. De lo contrario, el principio de interpretación conforme vaciaría de contenido el principio de reserva legal. Vid. sentencia de la Sala Primera de 11 de marzo de 2008, 1 BvR 2074/05, apartado 153.

${ }^{70}$ MÜLLER y CHRISTENSEN, 2002, p. 106.

71 Vid., por todos, GARCÍA DE ENTERRÍA, 1983, pp. 95-103. Para una temprana utilización de la doctrina de la interpretación conforme respecto a una ley postconstitucional vid. Tomás DE LA QUADRA-SALCEDO FERNÁNDEZ DEL CASTILLO, "Posible inconstitucionalidad de la Ley de Impuestos Especiales (Inconstitucionalidad y principio de interpretación conforme a la Constitución)", Revista Española de Derecho Administrativo, núm. 28, 1981, pp. 41-62.

72 STC 4/1981, FJ 4.

73 JIMÉNEZ CAMPO, 2001, p. 61; CANARIS, 2002, p. 66.

74 DE OTTO, 1988, p. 80; HESSE, 1999, p. 31. 
que dicha norma fundamental "representa, como fuente común, el vínculo entre todas las diversas normas que integran un determinado orden" 75 , se puede considerar que se trata, en realidad, del mismo fundamento.

El principio de interpretación conforme a la Constitución tuvo una importante función a la hora de garantizar la continuidad del ordenamiento, es decir, la conservación formal de la legalidad preconstitucional, salvo incompatibilidad insalvable con el texto constitucional. La disposición derogatoria de la Constitución española de 1978 derogó expresamente diversas leyes anteriores, así como cuantas disposiciones se opusieran a lo establecido en el texto constitucional. No obstante, el Tribunal Constitucional español precisó que la derogación por motivos materiales de las disposiciones jurídicas preconstitucionales solo procedía declararla "en aquellos casos en que las normas preconstitucionales — aun en el supuesto de que respondan a principios diversos - no pu[diera]n interpretarse de acuerdo con la Constitución por ser de un contenido incompatible con la misma" ${ }^{76}$.

Ambas tareas, la apreciación de la fuerza derogatoria de la Constitución y la adaptación del contenido de las disposiciones jurídicas preconstitucionales formalmente no derogadas a los valores y principios de aquella, en virtud del principio de interpretación conforme, fueron encomendadas al juez ordinario ${ }^{77}$. La interpretación conforme era el instrumento que garantizaba la continuidad del ordenamiento salvaguardando la supremacía de la Constitución: así se descartaban las soluciones extremas, tanto la conservación intacta de la legalidad ordinaria preconstitucional como el vacío normativo resultante de una ruptura abrupta con el pasado ${ }^{78}$.

Debido a la rápida consolidación de la jurisdicción constitucional a partir de 1980, la doctrina jurídica ha prestado más atención a la práctica de la interpretación conforme a la Constitución por esa jurisdicción que por la jurisdicción ordinaria ${ }^{79}$. Dos de los ámbitos en los que más se sintió la fuerza de irradiación de la Constitución fueron el derecho administrativo y el derecho penal. La tarea de replantear, depurar y ajustar a la Constitución un amplio conjunto de instituciones jurídicas y categorías dogmáticas de derecho administrativo largo tiempo utilizadas, como la relación de sujeción especial, las formas de autotutela administrativa y, en general, la posición

75 Hans KELSEN, Teoría general del Derecho y del Estado, 2. a ed. 1958, 5. a reimpresión 1995, UNAM, México, pp. 130-131. Vid. a este respecto Norberto BOBBIO, Teoría general del derecho, $1 .^{\mathrm{a}}$ ed. 1991, 4. ${ }^{\mathrm{a}}$ reimpresión 1996, Debate, Madrid, pp. 181-182.

76 STC 4/1981, FJ 5.

77 SSTC 62/1982, FJ 3; y 19/1983, FJ 3.

78 Ello se puso de manifiesto en diversas sentencias del Tribunal Constitucional: "en tanto no se dicten las leyes orgánicas que desarrollen el derecho constitucional subsistirá la legislación preconstitucional siempre que permita una interpretación conforme a la Constitución” (STC 47/1983, FJ 3). El criterio fue reiterado en la STS 10/12/1985, Ar. 6239.

79 El mejor estudio sobre la técnica de la interpretación conforme en sede constitucional es el de LÓPEZ BOFILL, 2004; vid. también Francisco Javier DÍEZ REVORIO, Las sentencias interpretativas del Tribunal Constitucional, Lex Nova, Valladolid, 2001. 
jurídica peculiar de la Administración pública, duró décadas ${ }^{80}$. Como ámbito paradigmático, la plena constitucionalización del derecho administrativo sancionador es un proceso que ha ocupado a la jurisdicción constitucional, a la jurisdicción ordinaria y al legislador durante décadas, hasta que el alcance de cada uno de los principios del derecho penal en el ámbito administrativo ha sido debidamente apreciado en el plano dogmático y las consecuencias resultantes incorporadas a la regulación de los múltiples regímenes sancionadores sectoriales existentes ${ }^{81}$.

Ahora bien, la interpretación conforme a la Constitución no es un fenómeno transitorio, circunscrito o centrado en las leyes preconstitucionales. La complejidad del sistema de fuentes y la actual legislación motorizada (que en España incluye diecisiete asambleas legislativas autonómicas y otros tantos legisladores de urgencia, además de los estatales) reclaman un uso constante de la técnica de la interpretación conforme a la Constitución también en relación con las leyes postconstitucionales, en todos los ámbitos, incluida la distribución constitucional de competencias entre los poderes territoriales: baste recordar las numerosas interpretaciones conformes que jalonan la STC 31/2010, de 28 de junio ${ }^{82}$. En la jurisdicción constitucional las interpretaciones conformes no solo son explícitas, sino que se llevan a menudo al fallo de la sentencia, en aras de la seguridad jurídica, lo que incrementa su visibilidad.

En cambio, la interpretación conforme por el Tribunal Supremo español es una práctica que apenas ha sido cartografiada o valorada doctrinalmente. Pese a todo, su estatus jurídico y dogmático es incontrovertido. Los Jueces y Tribunales están obligados a interpretar y aplicar las leyes y los reglamentos "según los preceptos y principios constitucionales, conforme a la interpretación de los mismos que resulte de las resoluciones dictadas por el Tribunal Constitucional en todo tipo de procesos" (art. 5.1 LOPJ). Además, solo pueden plantear la cuestión de inconstitucionalidad "cuando

80 Vid. a este respecto, con ejemplos ilustrativos, Silvia DEL SAZ, "La crisis de la autotutela en los actos administrativos y su auge en los actos privados", Revista de Administración Pública, núm. 129, 1992, pp. 241-267; Fernando LÓPEZ RAMÓN, "Límites constitucionales de la autotutela ejecutiva”, Revista de Administración Pública, núm. 115, 1988, pp. 57-97; y Rafael GÓMEZ-FERRER MORANT, "Incidencia de la Constitución sobre el Derecho administrativo", Revista de Administración Pública, núm. 150, 1999, pp. 159-208.

81 Incluso se ha criticado la "frivolidad" de esa constitucionalización, por considerarla "auténtica falsificación hermenéutica" y "sumisión impuesta —no pasivamente aceptada - por el Tribunal Constitucional a determinados principios penales de rango constitucional". Vid. Alejandro NIETO, Derecho administrativo sancionador, . $^{a}$ ed., Tecnos, Madrid, 2012, pp. 565, 575.

${ }^{82}$ Por poner dos ejemplos adicionales, la STC 50/1999 declaró que los arts. 36.2 y 36.3 de la Ley 30/1992 de Régimen Jurídico y de Procedimiento Administrativo Común "son constitucionales interpretados en el sentido de que la obligación de traducir al castellano que en los mismos se contienen no se extiende a los documentos, expedientes o partes de los mismos que vayan a surtir efectos en otra Comunidad Autónoma en la que la lengua en la que dichos documentos hayan sido redactados tenga también carácter cooficial". Para otro ejemplo con relevancia para el derecho administrativo analizado doctrinalmente, vid. Francisco Javier FERNÁNDEZ GONZÁLEZ, "La comunicación previa a la interposición del recurso contencioso-administrativo: su interpretación conforme a la Constitución (Comentario a la Sentencia del Tribunal Constitucional 76/1996, de 30 de abril)", Revista de Estudios de la Administración Local y Autonómica, núm. 271-272, 1996, pp. 889-902. 
por vía interpretativa no sea posible la acomodación de la norma al ordenamiento constitucional" (art. 5.3 LOPJ). Existe, en suma, un claro mandato legal de interpretación conforme. También el Tribunal Supremo reitera el principio de interpretación de la legalidad ordinaria de conformidad con la Constitución ${ }^{83}$.

Determinar en qué grado y de qué forma los Jueces y Tribunales de la jurisdicción contencioso-administrativa, y sobre todo su cúspide, el Tribunal Supremo, aplican el principio de interpretación conforme no es una cuestión metodológicamente sencilla; entre otras razones, puede haber interpretación conforme a la Constitución inconsciente u oculta bajo otros cánones de interpretación, como el criterio sistemático. Con esas limitaciones, un rastreo, seguramente incompleto y fragmentario, efectuado hace una década en el seno de la jurisprudencia de la Sala de lo Contencioso-Administrativo del Tribunal Supremo español, sugiere una cierta desconexión entre la teoría y la realidad ${ }^{84}$. Y eso pese a que la práctica de la interpretación conforme a la Constitución tendría que sobresalir en la jurisdicción contencioso-administrativa y sobre todo en su cúspide: se trata de la jurisdicción que maneja un mayor número de normas, de muy diversos autores y aprobadas en momentos muy distintos, y todas ellas inciden directamente en las relaciones entre los ciudadanos y los poderes públicos, que son ámbitos sensibles a los derechos fundamentales y al resto de valores y principios reconocidos en la Constitución.

La transformación del recurso de casación contencioso-administrativo introducida en $2015^{85}$ podría quizá modificar esa realidad para el futuro, o cuando menos facilitar la tarea de cartografiado de la interpretación conforme en la jurisprudencia del Tribunal Supremo ${ }^{86}$. Por una parte, la sentencia que resuelve el recurso de casación admitido a trámite por tener interés casacional objetivo debe contener un fundamento en el que se fije expresamente la doctrina que se formula: por ejemplo, la interpretación de la ley que considere adecuada. Por otra parte, las partes podrían impulsar directa o indirectamente la práctica de la interpretación conforme. No obstante, las posibilidades son limitadas. Ninguno de los supuestos legales de interés casacional objetivo está relacionado directamente con la realización de una interpretación conforme. Dos previsiones de posible interés casacional objetivo podrían permitir la solicitud directa o indirecta de interpretaciones conformes a la Constitución, aunque en condiciones limitadas: cuando la resolución impugnada resuelva un debate que haya versado sobre la validez constitucional de una norma con rango de ley, sin que

83 STS 10/12/1985, Ar. 6239.

84 Vid. ARZOZ SANTISTEBAN, 2010, pp. 638-643. Unos resultados también modestos en Alemania resultan del estudio de VOSSKUHLE, 2000, p. 194. Su trabajo se centra en la jurisprudencia del Bundesgerichtshof, el Tribunal Supremo Federal alemán competente en materia civil y penal. En España, puede haber una utilización más amplia de la interpretación conforme en el contencioso-electoral, jurisprudencia específica que no he estudiado.

85 En España, el recurso de casación contencioso-administrativo es ahora un instrumento para la formación de jurisprudencia. Ya no basta con la alegación de una infracción del ordenamiento jurídico, ahora también hay que acreditar un interés casacional objetivo y el Tribunal Supremo debe así apreciarlo y motivarlo expresamente en el auto de admisión.

86 Agradezco esta reflexión a Miguel Azpitarte Sánchez. 
la improcedencia de plantear la pertinente cuestión de inconstitucionalidad aparezca suficientemente esclarecida, y cuando la resolución impugnada interprete y aplique aparentemente con error y como fundamento de su decisión una doctrina constitucional ${ }^{87}$.

Por tanto, si, como hipótesis de trabajo y al menos para el pasado, se da por buena la antes referida desconexión entre teoría y realidad, la pretendida centralidad del principio de interpretación conforme a la Constitución no se corrobora en la práctica jurisdiccional de la Sala de lo Contencioso-Administrativo del Tribunal Supremo español. ¿Cómo se explica esa aparente contención?

Una posible explicación es la estratégica: los Jueces y Tribunales no se sentirían cómodos con la operación, quizá por su complejidad y porque sus decisiones corren con ello un riesgo mayor de ser impugnadas y revisadas por instancias superiores (o, en última instancia, por el Tribunal Constitucional); y optan en consecuencia por dos estrategias minimizadoras de la interpretación conforme: ceñirse a aplicar directamente la interpretación que de los preceptos constitucionales "resulte de las resoluciones dictadas por el Tribunal Constitucional" o bien plantear la cuestión de inconstitucionalidad siempre que tengan dudas sobre la constitucionalidad de una disposición legal.

Otra posible explicación es la institucional: la interpretación conforme a la Constitución se introduce en el terreno constitucionalmente reservado a otros poderes, en el terreno del autor de la norma (el legislador) o bien en el terreno de quien tiene el monopolio de su control (el Tribunal Constitucional). Esa modalidad de interpretación conforme les permite sobre el papel ampliar el alcance de sus poderes ordinarios, pero no es necesariamente una vía del agrado de los jueces y tribunales. Sea por estrategia o por convencimiento sobre su función en el sistema jurídico, los órganos judiciales no están siempre deseosos de agotar sus poderes, si ello implica corregir o interferir con la función constitucional de otros órganos del Estado.

Además, la posición de los jueces y tribunales con respecto a las leyes preconstitucionales es distinta de la posición que ostentan con respecto a las leyes postconstitucionales. El mandato de conservación de las leyes preconstitucionales por miedo a un vacío normativo, repudiando solo los sentidos incompatibles con la Constitución, justificaba la práctica de la interpretación conforme, tanto por el Tribunal Constitucional como por los órganos judiciales. Ese tipo de decisiones no creaba generalmente oposición en los operadores jurídicos. Por lo demás, la alternativa era considerarlas derogadas o bien promover la declaración de su incompatibilidad por el Tribunal Constitucional, mediante una cuestión de inconstitucionalidad. Si el órgano judicial era competente para inaplicar la ley preconstitucional por considerarla (plenamente) incompatible con la Constitución, no planteaba objeciones que también pudiera inaplicarla solo parcialmente, restringiendo o adaptando su programa normativo.

\footnotetext{
${ }^{87}$ Art. 88.2, letras d) y e), de la Ley de la Jurisdicción Contencioso-Administrativa.
} 
En cambio, la naturaleza de las leyes postconstitucionales es distinta y ello tiene que reflejarse en su régimen jurídico y en la actitud de jueces y tribunales. Las leyes postconstitucionales son expresión de la voluntad popular y se presumen legítimas, mientras el Tribunal Constitucional no diga lo contrario, y eso debería ser a todos los efectos, no solo a los efectos de su validez, sino también a los de su eficacia. Cuando un órgano judicial interpreta una disposición legal de conformidad con la Constitución, con la consecuencia de que se restringe el programa normativo adoptado por el legislador democrático, equivale a una declaración parcial de nulidad del contenido de la ley. El juez se convierte así en "dominus de la ley, so pretexto de la Constitución" ${ }^{88}$. Si la opción del constituyente por mantener concentrado el juicio de constitucionalidad de las normas de rango legal se basa, según la jurisprudencia constitucional, en el principio de seguridad jurídica y en el respeto a la obra del legislador, esas consideraciones no deberían olvidarse cuando un órgano judicial pretende realizar una interpretación conforme a la Constitución.

En el modelo europeo el control de constitucionalidad es concentrado y no se admiten otro tipo de controles (difusos) por los mismos motivos. Si "el constituyente quiso sustraer al Juez ordinario la posibilidad de inaplicar una ley ante un eventual juicio de incompatibilidad con la Constitución [...], por corresponder de forma exclusiva la depuración del ordenamiento leal, vigente la Constitución, al Tribunal Constitucional" ${ }^{89}$; si "el juicio adverso a que tal examen pueda eventualmente conducirlos no los faculta para dejar sin más de aplicarlas, sino sólo para cuestionarlas ante este Tribunal" ${ }^{90}$, entonces la utilización de la técnica de la interpretación conforme a la Constitución no parece casar bien con el control concentrado: a fin de cuentas la interpretación conforme equivale a una declaración parcial de inconstitucionalidad, con la consiguiente inaplicación parcial del contenido normativo de dis-

88 Expresión que utiliza JIMÉNEZ CAMPO, 1992, p. 12 a propósito de la analogía secundum constitutionem, pero, a nuestro juicio, nada impide extrapolar la misma reflexión a la interpretación conforme.

89 STC 58/2004, FJ 7.

90 Véase la caracterización que hizo la STC 17/1981, FJ 1: "La estricta aplicación del principio de jerarquía permitiría al juez resolver el dilema en que lo situaría la eventual contradicción entre la Constitución y la ley con la simple inaplicación de ésta, pero ello hubiera implicado someter la obra del legislador al criterio tal vez diverso de un elevado número de órganos judiciales, de donde podría resultar, entre otras cosas, un alto grado de inseguridad jurídica. El constituyente ha preferido, para evitarlo, sustraer al juez ordinario la posibilidad de inaplicar la ley que emana del legislador constituido, aunque no la de cuestionar su constitucionalidad ante este Tribunal que, en cierto sentido, es así, no sólo defensor de la Constitución, sino defensor también de la ley. La defensa de la Constitución frente a las eventuales extralimitaciones de los órganos dotados de poder para crear normas de carácter general corresponde, en primer lugar, a los Jueces y Tribunales, que han de negar validez, a las normas reglamentarias que sean contrarias a la Constitución, inaplicándolas, y están facultados para inaplicar también incluso las normas legales que adolezcan del mismo defecto, cuando sean anteriores a la Constitución. La supremacía de ésta obliga también a los jueces y tribunales a examinar, de oficio o a instancia de parte, la posible inconstitucionalidad de las leyes en las que, en cada caso concreto, hayan de apoyar sus fallos, pero, en defensa, como antes se dice, de la dignidad de la ley emanada de la representación popular, el juicio adverso a que tal examen pueda eventualmente conducirlos no los faculta para dejar sin más de aplicarlas, sino sólo para cuestionarlas ante este Tribunal.” 
posiciones legales. La interpretación conforme a la Constitución de las disposiciones de rango legal comparte con el control de constitucionalidad reservado al Tribunal Constitucional varios elementos: el parámetro y el objeto, solo cambia el sujeto que realiza cada operación. No extrańa, pues, que el Tribunal Constitucional haya asumido con especial celo la "defensa de la dignidad de la ley" frente a la inaplicación judicial de leyes estatales o autonómicas, protegiendo por la vía del recurso de amparo a los particulares (e incluso a las personas jurídico-públicas) que vieron que la ley en la que fundamentaban su pretensión era inaplicada por un órgano judicial. ${ }^{91}$ La inaplicación judicial de una ley por motivos de inconstitucionalidad, sean estos más o menos contenidos o manifiestos, es siempre una interferencia con el control concentrado de constitucionalidad ${ }^{92}$.

En Alemania, de cuyo ordenamiento tanta inspiración constitucional se ha recibido en Espańa y cuya doctrina de la interpretación conforme se importó al inicio de la etapa constitucional española, existe una corriente crítica sobre la práctica de la interpretación conforme por los jueces y tribunales ordinarios. Examinemos brevemente algunos de los problemas que allí se señalan.

Un primer problema son las dudas sobre el fundamento dogmático de la interpretación conforme por los jueces y tribunales ordinarios. Se cuestiona que el postulado de la unidad del ordenamiento y su estructura jerárquica fundamenten que un juez o tribunal ordinario proceda a la interpretación conforme. El postulado de la unidad del ordenamiento prohíbe una interpretación incompatible con la Constitución, pero no obligaría a una interpretación conforme. La otra idea que los defensores de la interpretación conforme aducen a este respecto, el principio de conservación de las leyes (favor legis), no sería concluyente. Aunque se arguya que es preferible una interpretación conforme para evitar un vacío normativo y para evitar sobrecargar al legislador con pequeñas y numerosas correcciones de detalle, la deferencia hacia el legislador puede convertirse rápidamente en lo contrario, si lo posible constitucionalmente es declarado por el juez como lo querido realmente, esto es, crea derecho, en lugar de invalidar por inconstitucional lo querido por el legislador. Del principio de conservación de las leyes no se puede deducir un mandato de interpretación conforme en todo caso, siempre que haya dudas al respecto. Más bien el principio obliga a considerar, teniendo en cuenta todas las circunstancias del caso concreto, si la norma debe ser "salvada" en interés de un ordenamiento jurídico que pueda funcionar

91 SSTC 17/1981, FJ 1; 23/1988, FJ 1; 173/2002, FJ 4; 187/2012, FJ 2; y 195/2015, FJ 3.

92 Por ello, no parece congruente con el control concentrado de constitucionalidad que la Constitución configuró el poder de inaplicación que en la STC 102/2016 el Tribunal Constitucional reconoció a los Jueces y Tribunales con respecto a las leyes autonómicas que no se acompasen a la modificación de las leyes básicas estatales. El argumento de la prevalencia del derecho estatal y la consecuencia del desplazamiento de la ley autonómica por una ley integrada en el bloque de constitucionalidad tampoco resulta convincente: el entero texto constitucional goza de supremacía y eso no fundamenta un poder judicial de inaplicación de las leyes incompatibles, p. ej., con los derechos fundamentales, por muy manifiesta que sea la incompatibilidad. 
correctamente o debe ser devuelta al legislador para que elabore una ley que no sea incompatible con la Constitución ${ }^{93}$.

En segundo lugar, se aprecian diversos peligros en la interpretación conforme por jueces y tribunales ordinarios. Un peligro es la acumulación de funciones. A los jueces y tribunales ordinarios no solo les competiría la función de colaborar en la realización de la ley mediante la creación de derecho, sino, también, la función de velar por la conformidad con la Constitución de la interpretación de las normas aprobadas por el legislador reduciendo en su caso el programa normativo decidido por este, esto es, "descreando" derecho. Ambas funciones se fundirían en una especie de "supercompetencia”, con la cual, sin más, se puede socavar la intención reguladora del legislador democrático. Un segundo peligro es la pérdida de autoridad debido a las interpretaciones divergentes de los distintos jueces y tribunales ordinarios. La operación de interpretación conforme es compleja y los resultados no son siempre previsibles, por lo que, siendo los intérpretes numerosos, el riesgo de decisiones divergentes es claro. Otro peligro es que la interpretación conforme no permite disciplinar al legislador. El legislador teme más una sentencia de inconstitucionalidad e, incluso, una sentencia interpretativa del Tribunal Constitucional que atraen la atención de la opinión política y pública, que una interpretación conforme de un juez o tribunal ordinario que salva la constitucionalidad de la ley y que solo es conocida por un círculo pequeño de operadores jurídicos: esa interpretación conforme solo excepcionalmente provocará una corrección legislativa. Sin sentencias del más alto Tribunal que aprecien vulneraciones de la Constitución o constaten la insuficiente precisión o cuidado de la técnica legislativa, el legislador no recibe estímulo para legislar con más cuidado y atención a la Constitución ${ }^{94}$.

Algunos autores alemanes van más allá y a partir de las dudas o los peligros mencionados construyen objeciones dogmáticas a la interpretación conforme. Así, Ulrike Lembke niega la posibilidad de una interpretación conforme de la ley como método de compatibilización de las normas jurídicas mediante la interpretación, pues cuestiona cada uno de los "títulos" legitimadores aducidos en favor de dicha técnica: la presunción de constitucionalidad de las leyes, el respeto de las decisiones legislativas mediante la conservación de la norma, la unidad del ordenamiento jurídico, la primacía de la Constitución, la protección de los derechos fundamentales, etc. ${ }^{95}$ No obstante, aunque se reconozca la dificultad de refutar esas objeciones, la interpretación conforme de la ley sigue encontrando buena acogida y caracteriza la manera alemana de pensar el ordenamiento jurídico desde la Constitución ${ }^{96}$.

93 VOSSKUHLE, 2000, pp. 182-184.

94 VOSSKUHLE, 2000, pp. 184-190.

95 Ulrike LEMBKE, Einheit aus Erkenntnis? Zur Unzulässigkeit der verfassungskonformen Gesetzesauslegung als Methode der Normenkompatibilisierung durch Interpretation, Duncker \& Humblot, Berlín, 2009.

96 Matthias JESTAEDT, "Phänomen Bundesverfassungsgericht. Was das Gericht zu dem macht, was es ist”, en Matthias Jestaedt, Oliver Lepsius, Christoph Möllers y Christoph Schönberger, 
Esta discusión crítica sobre el fundamento último de la interpretación conforme, alentada por un sector de la doctrina alemana, puede servirnos de antesala a una reflexión más general sobre los tipos de controles sobre la ley y la práctica de las distintas modalidades de interpretación conforme.

\subsection{La conexión entre el poder de inaplicación de la ley y la práctica de la interpretación conforme}

Llegados a este punto, podemos explorar la relación entre las modalidades de interpretación conforme y los distintos controles sobre la ley que existen en el ordenamiento jurídico. A partir de algunas de las consideraciones realizadas anteriormente se puede formular la hipótesis de que hay una relación, o una conexión, entre la disposición de un poder de control sobre la ley y la predisposición a la práctica de la interpretación conforme. Aunque en el ordenamiento jurídico español los órganos judiciales estén de lege data legitimados para practicar la interpretación conforme a la Constitución de las disposiciones de rango legal, su incompetencia para inaplicar esas disposiciones por motivos de constitucionalidad les inhibe en la práctica de un uso proactivo de la interpretación conforme como técnica de coordinación normativa. En cambio, la jurisdicción constitucional, que por definición debe resolver de manera continua pretensiones impugnatorias directas contra disposiciones de rango legal fundamentadas en motivos de inconstitucionalidad, no ve obstáculo normativo o institucional alguno en utilizar la interpretación conforme: es más, es la técnica que idealmente le permite conciliar la supremacía de la Constitución y la deferencia hacia el legislador democrático ${ }^{97}$.

Esas consideraciones pueden explicar también por qué el Tribunal Constitucional español no atendió a la exigencia explícita que en este sentido se contiene, todavía hoy, en el art. 5.3 LOPJ, antes citado, liberando a los Jueces y Tribunales de la necesidad de acreditar la imposibilidad de superar la duda de inconstitucionalidad por vía interpretativa ${ }^{98}$. Aunque esa exigencia no estaba recogido entre los requisitos de admisión de la cuestión de inconstitucionalidad contenidos en el art. 35 de la Ley

Das entgrenzte Gericht. Eine kritische Bilanz nach sechzig Jahren Bundesverfassungsgericht, Berlín, Suhrkamp. 2011, pp. 77-157 (p. 140).

${ }_{97} \mathrm{Y}$ en el plano estratégico y actitudinal también ofrece ventajas: favorece soluciones de consenso ad intra, en la jurisdicción constitucional, y ad extra, con respecto a mayoría y minoría parlamentaria.

98 Vid., entre otros, SSTC 222/1992, FJ 2; y 126/1997, FJ 3. El legislador de la Ley Orgánica del Poder Judicial, aprobada en 1985, tomó la exigencia de la justificación de la imposibilidad de una interpretación conforme (art. 5.3) de una temprana sentencia del Tribunal Constitucional que así lo había insinuado (STC 14/1981, de 29 de abril, FJ 1: como reza su numeral, era la decimocuarta sentencia de la historia de la jurisdicción constitucional española). Al respecto puede verse Manuel MEDINA GUERRERO, “Art. 35”, en Juan Luis Requejo Pagés (coord.), Comentarios a la Ley Orgánica del Tribunal Constitucional, Tribunal Constitucional-Boletín Oficial del Estado, Madrid, 2001, pp. 511-531 (pp. 522-523). 
Orgánica del Tribunal Constitucional (LOTC), única ley — junto a la Constitución- a la que el Tribunal Constitucional está sometido (art. 1 LOTC), no parece que solo esa fuera la razón determinante. Tampoco que aquella flexibilización fuera motivada simplemente por una especie de principio pro actione o por un afán de facilitar el control incidental de normas: el Tribunal Constitucional no ha tenido reparo alguno hasta la fecha en mantener un escrutinio estricto sobre el cumplimiento de los requisitos de admisión de las cuestiones de inconstitucionalidad, desde los lógicomateriales propios del control incidental (indicación de la duda de constitucionalidad y justificación de su relevancia para la resolución del litigio) a los estrictamente procedimentales (conclusión del procedimiento a quo y audiencia a las partes).

Si la sujeción a la Constitución fuera un simple problema técnico-jurídico de aplicación e interpretación de normas legales, el Tribunal Constitucional podría haber exigido que el órgano judicial promotor de una cuestión de inconstitucionalidad acreditara con mayor o menor intensidad por qué la duda de inconstitucionalidad planteada no podía superarse por vía interpretativa y/o mediante una interpretación conforme, como habitualmente hace con otros problemas técnico-jurídicos que pueden condicionar el juicio de relevancia de la cuestión de inconstitucionalidad (problemas procesales o de derecho temporal), de forma que quedara razonablemente justificado que la intervención de la jurisdicción constitucional es imprescindible. Pero la conformación de una interpretación conforme verosímil está estrechamente ligada al fondo de la duda de constitucionalidad que el órgano judicial abriga. Y si la sujeción a la Constitución fuera un simple problema técnico de aplicación e interpretación de normas o si pudiera considerase a cualquier órgano judicial suficientemente avezado en la interpretación de la Constitución, no se habría creado una jurisdicción constitucional especializada.

En cambio, las otras modalidades de interpretación conforme que, en principio, solo pueden practicar los órganos judiciales se corresponden con controles difusos expresamente reconocidos a los órganos judiciales. En España, los órganos judiciales están facultados para inaplicar las disposiciones internas, incluso de rango legal, que sean incompatibles con el derecho de la Unión Europea ${ }^{99} \mathrm{o}$ bien con lo establecido en un tratado internacional válidamente celebrado por España ${ }^{100}$. A la jurisdicción constitucional le pueden quizá no agradar esos controles difusos en cuanto recaen sobre la ley y rivalizan por tanto con su control de constitucionalidad; pero en la medida en que no utilizan el mismo parámetro y no excluyen su propio control, no debería albergar especiales prevenciones contra su ejercicio, siempre, claro está, que por su frecuencia y anticipación temporal mermen sus posibilidades de intervención y con ello su relevancia, sobre todo en los supuestos de "doble vicio" (o "doble

99 Se trata de la llamada "doctrina Simmenthal" del Tribunal de Justicia: vid. sentencia de 9 de marzo de 1978, as. 106/77, Simmenthal, apartado 24; en el mismo sentido, entre muchas, la sentencia de 18 de julio de 2007, Lucchini, as. C-119/05, apartado 61.

100 Vid. supra nota 66. 
prejudicialidad") ${ }^{101}$. No obstante, eso no significa que le resulte indiferente el correcto ejercicio del poder de inaplicación de la ley por motivos distintos de los de constitucionalidad ${ }^{102}$. En cualquier caso, las suspicacias siempre serán menores cuando el órgano judicial opte por la técnica de la interpretación conforme (al derecho de la Unión Europea o al tratado internacional), que a fin de cuentas evita la inaplicación de la ley y procura por tanto su conservación; dejando la vía expedita a un control adicional de constitucionalidad.

\section{CONCLUSIÓN}

La pluralidad de principios de interpretación conforme que existen en el ordenamiento jurídico español, así como en otros ordenamientos de su entorno, es expresión de la creciente interacción entre sistemas jurídicos. En particular es consecuencia de tres procesos que convergen en la segunda mitad del siglo xx en el Estado de derecho: la constitucionalización del ordenamiento jurídico, la vinculación del Estado constitucional al derecho internacional de los derechos humanos y la europeización del ordenamiento jurídico estatal.

La variedad existente de modalidades de interpretación conforme es crucial para el entendimiento de las funciones y las competencias de los órganos jurisdiccionales, así como para la teoría del método jurídico. Las reflexiones realizadas en este trabajo han pretendido, por un lado, resaltar el desafío que para la labor jurisdiccional y la dogmática jurídica constituye la pluralidad de tareas de interpretación conforme que caracterizan al sistema jurídico propio de un Estado constitucional, abierto al derecho internacional de los derechos humanos e integrado en una organización supranacional como la Unión Europea; y, por otro lado, apuntar los elementos comunes de una teoría general de la interpretación conforme.

El principio de interpretación conforme a la Constitución es el modelo a partir del cual se configuraron otras modalidades de interpretación conforme que existen en la actualidad. Aunque conserva la enorme relevancia dogmática que tradicional-

101 A la jurisdicción constitucional espańola no le ha preocupado hasta la fecha (vid. en cambio la sentencia 269/2017 de la Corte Costituzionale) que, en los supuestos de "doble vicio" (vicios de constitucionalidad y europeidad), el planteamiento de cuestiones prejudiciales ante el Tribunal de Justicia merme en la práctica las posibilidades de intervención de la jurisdicción constitucional. La regla en el ordenamiento constitucional espańol es la prioridad, basada en argumentos lógico-normativos, de la cuestión prejudicial europea sobre la cuestión de inconstitucionalidad pues esta solo se puede promover sobre normas aplicables al litigio (ATC 168/2016, FJ 4).

102 En varias ocasiones ha declarado la nulidad de decisiones judiciales que habían dejado de aplicar disposiciones legales por considerarlas incompatibles con el derecho de la Unión, sin haber seguido, en opinión del Tribunal Constitucional, los mecanismos que dispone el derecho de la Unión para establecer la interpretación definitiva de sus disposiciones, básicamente la solicitud de una decisión prejudicial del Tribunal de Justicia (art. 267 TFUE). Aunque su control recae las condiciones de ejercicio del poder judicial de inaplicación, que son independientes de la naturaleza o rango de la norma interna inaplicada, lo justifica en la "defensa de la dignidad de la ley". Vid. SSTC 58/2004 y 37/2019. 
mente le ha atribuido la doctrina jurídica, en cuanto responde al paradigma de la constitucionalización del ordenamiento jurídico, en los ordenamientos jurídicos que cuentan con un control concentrado de constitucionalidad su ejercicio se residencia preferentemente en la jurisdicción constitucional. Ese mayor protagonismo de la jurisdicción constitucional en la práctica de la interpretación conforme, en detrimento de la del poder judicial, a quien le corresponde la aplicación e interpretación cotidiana de la "legalidad ordinaria", podría explicar la aparente contradicción existente entre la tajante exclusión de la posibilidad judicial de inaplicar la ley propia de los modelos de control concentrado de constitucionalidad, por un lado, y la paralela e incondicional aceptación de la práctica judicial de la interpretación conforme a la Constitución, por otro lado: a fin de cuentas, al amparo de la técnica de la interpretación conforme el órgano judicial puede inaplicar o modular parte del programa normativo de una disposición de rango legal. Si la razón aducida para esa compatibilización es la supremacía de la Constitución, se incurre en cierta interferencia con el control concentrado de constitucionalidad cuando la disposición compatibilizada tiene rango legal.

En cambio, la interpretación conforme al derecho de la Unión Europea y, en su caso, a los tratados internacionales se sitúa en una encrucijada diferente a la de la interpretación conforme a la Constitución. En la actualidad el sistema concentrado de constitucionalidad de la ley convive con otros controles difusos sobre la ley, en garantía de una supralegalidad que ya no solo incluye la de rango constitucional. Paradójicamente, la interpretación conforme como técnica de coordinación normativa encaja mejor con los controles difusos de la ley por motivos distintos de la constitucionalidad, allí donde existen, pues esas modalidades de interpretación conforme modulan el poder que tiene el juez ordinario de inaplicar la ley por motivos distintos de la constitucionalidad y contribuyen al principio de conservación de la ley.

En cualquiera de sus modalidades, con independencia de que esté al servicio de la garantía de la supremacía de la Constitución, la primacía y efectividad del derecho de la Unión Europea o el cumplimiento de las obligaciones internacionales, el principio de interpretación conforme expresa en último término circunspección respecto al legislador democrático y reconocimiento de su prioridad en la concretización de la Constitución y en la ejecución de los compromisos internacionales del Estado. Cuando sea posible conferirle a la ley un sentido conforme a lo establecido en la "supralegalidad" definida como canon prioritario de interpretación, puede evitar soluciones más traumáticas como son la inaplicación de una ley o bien su cuestionamiento ante la instancia competente para su control.

\section{BIBLIOGRAFÍA}

Christina M. AKRIVOPOULOU, "The Jurisprudence of the ECtHR as a Common European Constitution", European Review of Public Law/Revue européenne de droit public, vol. 22, núm. 2, 2010, pp. 395-412. 
Ricardo ALONSO GARCÍA, "La interpretación del Derecho de los Estados conforme al Derecho Comunitario: las exigencias y límites de un nuevo criterio hermenéutico", Revista Española de Derecho Europeo, núm. 28, 2008, pp. 385-410.

- , "La interpretación del Derecho nacional en función de la entrada en vigor de las Directivas y de su fecha límite de transposición (o su trasposición anticipada)", Revista Española de Derecho Europeo, núm. 64, 2017, pp. 13-24.

-, "El control de convencionalidad: cinco interrogantes", Revista Española de Derecho Constitucional, núm. 119, 2020, pp. 13-51.

Joël ANDRIANTSIMBAZOVINA, "L'enrichissement mutuel de la protection des droits fondamentaux au niveau européen et au niveau national. Vers un contrôle de "fondamentalité»", Revue française de droit administratif, 2002, pp. 124-138.

Xabier ARZOZ SANTISTEBAN, "Interpretación conforme", en Juan Alfonso SANTAMARÍA PASTOR (dir.), Los principios jurídicos del Derecho administrativo, La Ley, Madrid, 2010, pp. 619-662.

—, La concretización y actualización de los derechos fundamentales, CEPC, Madrid, 2014.

José Manuel BANDRÉS SÁNCHEZ-CRUZAT, "La Carta Europea de la Autonomía Local en la jurisprudencia del Tribunal Supremo", Quaderns de Dret Local, núm. 20, 2009, pp. 7-22.

Rudolf BERNHARDT, "Völkerrechtliche Auslegung der Verfassung? Verfassungskonforme Auslegung völkerrechtlicher Verträge”, en Hans-Joachim CREMER, Thomas GIEGERICH, Dagmar RICHTER y Andreas ZIMMERMANN (eds.), Tradition und Weltoffentheit des Rechts - Festschrift für Helmut Steinberger, tomo I, Springer, Berlín, 2002, pp. 391-400.

Gerrit BETLEM, "The doctrine of consistent interpretation - Managing legal uncertainty", Oxford Journal of Legal Studies, vol. 22, núm. 3, 2002, pp. 397-418.

Gerrit BETLEM y André NOLLKAEMPER, "Giving effect to public international law and European Community law before domestic courts. A comparative analysis of the practice of consistent interpretation”, European Journal of International Law, vol. 14, núm. 3, 2003, pp. 569-589.

Robert BLACKBURN y Jörg POLAKIEWICZ (eds.), Fundamental Rights in Europe. The ECHR and its Member States, 1950-2000, Oxford University Press, Oxford, 2001.

Norberto BOBBIO, Teoría general del derecho, 1. ${ }^{a}$ ed. 1991, 4. ${ }^{a}$ reimpresión 1996, Debate, Madrid.

Winfried BRECHMANN, Die richtlinienkonforme Auslegung, Beck, Múnich, 1994.

Claus-Wilhelm CANARIS, "Die richtlinienkonforme Auslegung und Rechtsfortbildung im System der juristischen Methodenlehre", en Helmut KOZIOL y Peter RUMMEL (eds.), Im Dienste der Gerechtigkeit - Festschrift für Franz Bydlinski, Springer, Viena/Nueva York, 2002, pp. 47-103.

Manuel CALVO GARCÍA (ed.), Interpretación y argumentación jurídica. Trabajos del Seminario de Metodología Jurídica (volumen 1), PUZ, Zaragoza, 1995.

Cécile CASTAING, "L'extension du contrôle de conventionalité aux principes généraux du droit communautaire", Revue trimestrielle de droit européen, núm. 39, 2003, pp. 197-228.

Monica CLAES, The national courts' mandate in the European constitution, Hart, Oxford, 2006.

Tomás DE LA QUADRA-SALCEDO FERNÁNDEZ DEL CASTILLO, "Posible inconstitucionalidad de la Ley de Impuestos Especiales (Inconstitucionalidad y principio de interpretación conforme a la Constitución)", Revista Española de Derecho Administrativo, núm. 28, 1981, pp. 41-62.

Silvia DEL SAZ, "La crisis de la autotutela en los actos administrativos y su auge en los actos privados", Revista de Administración Pública, núm. 129, 1992, pp. 241-267.

Ignacio DE OTTO, Derecho constitucional. Sistema de fuentes, 2. ${ }^{\text {a }}$ ed. (y última), Ariel, Barcelona, 1988 (4. ${ }^{a}$ reimpresión de 1995).

Martje DE VISSER, Constitutional Review in Europe. A Constitutional Analysis, Hart, Oxford, 2015.

Jeanine DE VRIES REILINGH, L'application des Pactes des Nations Unies relatifs aux droits de l'homme de 1966, Basilea, 1998.

Francisco Javier DÍEZ REVORIO, Las sentencias interpretativas del Tribunal Constitucional, Lex Nova, Valladolid, 2001.

Francisco Javier FERNÁNDEZ GONZÁLEZ, "La comunicación previa a la interposición del recurso contencioso-administrativo: su interpretación conforme a la constitución (Comentario a la Sentencia del Tribunal Constitucional 76/1996, de 30 de abril)", Revista de Estudios de la Administración Local y Autonómica, núm. 271-272, 1996, pp. 889-902. 
Eduardo GARCÍA DE ENTERRÍA, La Constitución como norma y el Tribunal Constitucional, 3.a ed., Civitas, Madrid, 1983 (reimpresión 2001).

Javier GARCÍA ROCA, "El diálogo entre el Tribunal Europeo de Derechos Humanos y los tribunales constitucionales en la construcción de un orden público europeo", Teoría y Realidad Constitucional, núm. 30, 2012, pp. 183-224.

-, La transformación constitucional del Convenio Europeo de Derechos Humanos, Civitas-Thomson Reuters, Cizur Menor, 2019.

Rafael GÓMEZ-FERRER MORANT, "Incidencia de la Constitución sobre el Derecho administrativo", Revista de Administración Pública, núm. 150, 1999, pp. 159-208.

Christoph GRABENWARTER, Europäische Menschenrechtskonvention, 4a ed. C.H. Beck/Helbing Lichtenhahn/Manz, Múnich/Basilea/Viena, 2009.

Peter HÄBERLE, “Theorieelemente eines allgemeinen juristischen Rezeptionsmodells”, Juristenzeitung, 1992, pp. 1033-1043.

Konrad HESSE, Grundzüge des Verfassungsrechts, 20.a ed. (última), C.F. Müller, Heidelberg, 1999.

Juan IGARTUA SALABERRIA, Teoría Analitica del derecho (La interpretación de la Ley), Onate, IVAP, 1994.

Giulio ITZCOVICH, "The interpretation of Community Law by the European Court of Justice", German Law Journal, vol. 10, núm. 5, 2009, pp. 537-559.

Matthias JESTAEDT, "Phänomen Bundesverfassungsgericht. Was das Gericht zu dem macht, was es ist", en Matthias JESTAEDT, Oliver LEPSIUS, Christoph MÖLLERS y Christoph SCHÖNBERGER, Das entgrenzte Gericht. Eine kritische Bilanz nach sechzig Jahren Bundesverfassungsgericht, Berlín, Suhrkamp. 2011, pp. 77-157.

Javier JIMÉNEZ CAMPO, "Analogía secundum constitutionem", Revista del Centro de Estudios Constitucionales, núm. 13, 1992, pp. 9-30.

—, "Interpretación conforme a la Constitución", en Manuel ARAGÓN REYES (coord.), Temas básicos de Derecho Constitucional, tomo I, Civitas, Madrid, 2001.

Hans KELSEN, Teoría general del Derecho y del Estado, 2. a ed. 1958, 5. a reimpresión 1995, UNAM, México.

Jens $\mathrm{KOCH}$, "Die Einheit der nationalen Rechtsordnung und die europäische Privatrechtsangleichung", Juristen-Zeitung, núm. 6, 2006, pp. 277-284.

Karl LARENZ, Methodenlehre der Rechtswissenschaft, 2.a ed. Springer, Berlín, 1992 (verkürzte Studienausgabe de la 6. ${ }^{\text {a }}$ última edición de su obra, 1991).

Ińaki LASAGABASTER HERRARTE (dir.), Convenio Europeo de Derechos Humanos. Comentario sistemático, 4. ${ }^{\mathrm{a}}$ ed. Civitas, Madrid, 2021.

Ulrike LEMBKE, Einheit aus Erkenntnis? Zur Unzulässigkeit der verfassungskonformen Gesetzesauslegung als Methode der Normenkompatibilisierung durch Interpretation, Duncker \& Humblot, Berlín, 2009.

George LETSAS, A Theory of Interpretation of the European Convention on Human Rights, Oxford, Oxford University Press, 2007.

Diego J. LIÑÁN NOGUERAS, "El proyecto constitucional europeo y la interpretación de derechos y libertades en la Constitución española: ¿una nueva dimensión del art. 10.2 CE?”, en Pacis artes. Obra homenaje al Profesor Julio D. González Campo, vol. 1, Universidad Autónoma de Madrid, Madrid, 2005, pp. 933-946.

Hèctor LÓPEZ BOFILL, Decisiones interpretativas en el control de constitucionalidad de la ley, IVAPTirant lo Blanch, Valencia, 2004.

Antonio LÓPEZ CASTILLO y Jörg POLAKIEWICZ, "De la cuestión prejudicial de convencionalidad en marcha", Teoría y Realidad Constitucional, núm. 44, 2019, pp. 485-500.

Fernando LÓPEZ RAMÓN, "Límites constitucionales de la autotutela ejecutiva", Revista de Administración Pública, núm. 115, 1988, pp. 57-97.

Manuel MEDINA GUERRERO, "Art. 35", en Juan Luis REQUEJO PAGÉS (coord.), Comentarios a la Ley Orgánica del Tribunal Constitucional, Tribunal Constitucional-Boletín Oficial del Estado, Madrid, 2001, pp. 511-531.

Friedrich MÜLLER y Ralf CHRISTENSEN, Juristische Methodik, Band I: Grundlagen - Öffentliches

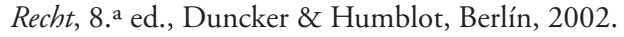


Alejandro NIETO, Derecho administrativo sancionador, 5a ed., Tecnos, Madrid, 2012.

Miguel Ángel PÉREZ ÁLVAREZ, Interpretación y jurisprudencia. Estudio del artículo 3.1 del Código Civil, Aranzadi, Pamplona, 1994.

Jörg POLAKIEWICZ, "The Status of the Convention in National Law", en Robert BLACKBURN y Jörg POLAKIEWICZ (eds.), Fundamental Rights in Europe. The ECHR and its Member States, 1950-2000, Oxford, Oxford University Press, 2001, pp. 31-53.

Michael POTACS, "Effet utile als Auslegungsgrundsatz", Europarecht, 2009, pp. 465-487.

Sacha PRECHAL, Directives in EC Law, $2^{\mathrm{a}}$ ed., Oxford, Oxford University Press, 2005, pp. 180-215.

Argelia QUERALT JIMÉNEZ, La interpretación de los derechos: del Tribunal de Estrasburgo al Tribunal Constitucional, CEPC, Madrid, 2008.

—, "Artículo 10.2", en Pablo PÉREZ TREMPS y Alejandro SÁIZ ARNÁIZ (dirs.), Carmen MONTESINOS PADILLA (coord.), Comentario a la Constitución Española: 40 aniversario 1978-2018: Libro-homenaje a Luis López Guerra, vol. 1, Tirant lo Blanch, Valencia, 2018, pp. 277-286.

Georg RESS, "Die richtlinienkonforme 'Interpretation' innerstaatlichen Rechts", Die Öffentliche Verwaltung, núm. 12, vol. 47, 1994, pp. 489-497.

Reinhard H. RIEGER, "Grenzen verfassungskonformer Auslegung", Neue Zeitschrift für Verwaltungsrecht, 2003, pp. 17-22.

José María RODRÍGUEZ DE SANTIAGO, Metodología del Derecho administrativo. Reglas de racionalidad para la adopción y el control de la decisión administrativa, Marcial Pons, Madrid, 2016.

Alejandro SÁIZ ARNÁIZ, La apertura constitucional al derecho internacional y europeo de los derechos humanos. El artículo 10.2 de la Constitución española, CGPJ, Madrid, 1999.

—, "Artículo 10.2. La interpretación de los derechos fundamentales y los tratados internacionales sobre derechos humanos", en Miguel RODRÍGUEZ PIÑERO Y BRAVO FERRER y María Emilia CASAS BAAMONDE (dirs.), Comentarios a la Constitución española. XL Aniversario de la Constitución, BOE-Fundación Wolters Kluwer Espańa-Ministerio de Justicia-Tribunal Constitucional, Madrid, 2018, pp. 230-254.

William A. SCHABAS, The European Convention on Human Rights. A Commentary, Oxford University Press, Oxford, 2015.

Karl-Peter SOMMERMANN, "Völkerrechtlich garantierte Menschenrechte als Maßstab der Verfassungskonkretisierung - Die Menschenrechtsfreundlichkeit des Grundgesetzes", Archiv des öffentlichen Rechts, vol. 114, 1989, pp. 391-422.

Andreas VOSSKUHLE, "Theorie und Praxis der verfassungskonformen Auslegung von Gesetzen durch Fachgerichte - Kritische Bestandaufnahme und Versuch einer Neubestimmung", Archiv des öffentlichen Rechts, vol. 125, 2000, pp. 177-201.

Christian WALTER, "Die Europäische Menschenrechtskonvention als Konstitutionalisierungsprozess", Zeitschrift für ausländisches öffentliches Recht und Völkerrecht, vol. 59, 1999, pp. 961-983.

Jerzy WRÓBLEWSKI, "An outline of a general theory of legal interpretation and constitutional interpretation", Acta Universitatis Lodziensis, Folia Iuridica 32, 1987, pp. 33-89.

Gero ZIEGENHORN, Der Einfluss der EMRK im Recht der EU-Grundrechtecharta, Duncker \& Humblot, Berlín, 2009. 